\title{
Spatial Distribution of Potentiated Synapses in Hippocampus: Dependence on Cellular Mechanisms and Network Properties
}

\author{
M. F. Yeckel and T. W. Berger \\ Department of Biomedical Engineering, Program in Neuroscience, University of Southern California, Los Angeles, \\ California 90089-1451
}

\begin{abstract}
Long-term potentiation (LTP) of synaptic transmission, studied intensively in reduced brain preparations such as hippocampal brain slices, is the leading candidate for the cellular/molecular basis of learning and memory. Serious consideration of LTP as underlying information storage in the intact brain, however, requires understanding how LTP can be induced selectively at specific synaptic sites in a neural system when the mechanisms underlying LTP are regulated by other structural and functional properties of the same neural system. In the studies reported here, we tested the hypothesis that different patterns of activity within the same population of entorhinal cortical afferents could lead to a selective potentiation of spatially distinct populations of synapses across different regions of the hippocampus, including those activated multisynaptically. We focused specifically on potentiation of direct, monosynaptic entorhinal input to dentate granule cells, which expresses an NMDA receptor-
\end{abstract}

dependent LTP, and on potentiation of indirect, disynaptic entorhinal input to CA3 pyramidal cells, which is transmitted by the mossy fiber projection of dentate granule cells and expresses an NMDA receptor-independent LTP. The principal findings of these experiments show that lower stimulation frequencies $(10-20 \mathrm{~Hz})$ of entorhinal cortical axons selectively induce LTP of mossy fiber input to CA3 transsynaptically via excitation of dentate granule cells, and that patterns of stimulation of that mimic neuronal firing in the entorhinal cortex during endogenous theta rhythm (five-impulse bursts at $200 \mathrm{~Hz}$, interburst intervals of $200 \mathrm{msec}$ ) induce LTP both monosynaptically for input to dentate granule cells and transsynaptically for mossy fiber input to CA3.

Key words: LTP; CA3; CA1; pyramidal cell; dentate gyrus; granule cell; mossy fiber; perforant path; entorhinal cortex; transsynaptic; in vivo; learning; memory
The most promising mechanism for the cellular/molecular basis of learning and memory is long-term potentiation (LTP) of glutamatergic synaptic transmission (Berger, 1984; Landfield and Deadwyler, 1988; Morris, 1989; Bliss and Collingridge, 1993). Intensive experimental study of this phenomenon has revealed that LTP can be expressed by each of the synaptic populations forming the intrinsic, input-output pathway of the hippocampus (entorhinal cortex to dentate granule cells, granule cells to CA3 pyramidal cells, and CA3 pyramidal cells to CA1 pyramidal cells), and that the induction of LTP at any of these synaptic sites is achieved when excitatory activity increases to a critical level (McNaughton et al., 1978; Wigstrom and Gustafsson, 1983; Kelso et al., 1986). In addition, there appear to be different "forms" of LTP based on evidence that more than one set of mechanisms can lead to synaptic potentiation. For example, LTP of entorhinal cortical input to dentate granule cells requires activation of the NMDA subtype of glutamate receptor, whereas LTP of dentate granule cell input to pyramidal cells of the $\mathrm{CA} 3$ region can be induced independently of NMDA receptor-mediated activity (Harris and Cotman, 1986; Wigstrom et al., 1986). The dynamics of the underlying cellular/molecular mechanisms place constraints on the

Received Sept. 5, 1997; revised Oct. 21, 1997; accepted Oct. 23, 1997.

This work was supported by National Institute of Mental Health Grants MH51722 and MH00343, the Human Frontiers Science Organization, and a National Research Service Award fellowship to M.F.Y. We thank Christian Perron for assistance with CSD analysis and Dr. Nicholas Poolos for a critical reading of this manuscript.

Correspondence should be addressed to Dr. Mark F. Yeckel, Division of Neuroscience, Baylor College of Medicine, Houston, TX 77030. E-mail: myeckel@bcm.tmc.edu

Copyright (C) 1997 Society for Neuroscience $\quad 0270-6474 / 97 / 180438-13 \$ 05.00 / 0$ patterns of afferent activity, which optimally induce synaptic potentiation. For example, NMDA receptor-dependent LTP is preferentially induced by high-frequency $(100-400 \mathrm{~Hz})$ bursts of excitatory activity, because temporal summation during the bursts is an efficient means for providing the depolarization of the postsynaptic neuron required to relieve the $\mathrm{Mg}^{2+}$ block of the NMDA channel (Collingridge et al., 1988).

To date, electrophysiological studies of LTP have focused primarily on identifying the cellular/molecular mechanisms underlying potentiation of synapses activated monosynaptically, which has necessitated the use of reduced preparations, such as in vitro slices and tissue cultures (Andersen et al., 1977; Malenka et al., 1988; Davies et al., 1989; Bekkers and Stevens, 1990; Foster and McNaughton, 1991). When considered in the context of the intact brain, however, additional factors related specifically to network properties may play essential roles in achieving the specific induction requirements for LTP (Berger and Sclabassi, 1988; Berger et al., 1997). For example, the level of depolarization that results from an excitatory event after its propagation through a multisynaptic pathway will be influenced substantially by the degree of progressive convergence or divergence in the series of anatomical projections comprising that circuit. Analogously, the temporal pattern of action potential activity expressed by any one neuron in a circuit will be determined strongly by the extent of nonlinear transformations that occur at preceding synaptic junctions. These considerations raise the possibility that patterns of activity that are ineffective for inducing LTP monosynaptically may be effective for other, transsynaptically activated, cells. This possibility is strengthened by the fact that different mechanisms underlie LTP of synaptic connections between different subregions of hippocampus, strongly 
suggesting that the most effective pattern of activity for inducing LTP varies for different populations of synapses.

In the studies reported here, we test the hypothesis that different patterns of activity within the same population of entorhinal cortical afferents can lead to selective potentiation of spatially distinct populations of synapses with the hippocampus, including LTP of synapses activated multisynaptically. Our studies of the hippocampus in vivo show that selective potentiation of different synaptic sites reflect different mechanisms of LTP induction, and that a combination of anatomical and physiological factors determines the spatiotemporal propagation of excitatory activity through intrinsic hippocampal pathways.

\section{MATERIALS AND METHODS}

Surgical preparation. Experiments were performed on adult, male New Zealand White rabbits anesthetized continuously with gaseous halothane $(1.5-2.0 \%)$ while body temperature was maintained at $37-39^{\circ} \mathrm{C}$. All experimental procedures were consistent with those outlined in National Institutes of Health publication 91-3207, Preparation and Maintenance of Higher Animals During Neuroscience Experiments.

The skull and dura overlying the parietal cortex, dorsal to the hippocampus, were removed, and bipolar stimulating microelectrodes (Epoxylite-insulated stainless steel 00 insect pins, with $250 \mu \mathrm{m}$ exposed tips and spaced 500-1000 $\mu \mathrm{m}$ apart) were positioned stereotaxically into medial perforant path fibers of the angular bundle. When examining the mossy fiber pathway, a concentric bipolar stimulating electrode (Rhodes Medical Instruments; $100 \mu \mathrm{m}$ diameter, modified so that the total exposed length was $\sim 350 \mu \mathrm{m}$ ) was lowered into the ventral two-thirds of the hilus of the ipsilateral dentate gyrus adjacent to the CA3c region.

Stainless steel recording microelectrodes (etched and insulated insect pins; $10 \mu \mathrm{m}$ exposed tip; $1 \mathrm{M} \Omega$ measured at $135 \mathrm{~Hz}$ in vitro) or tungsten recording microelectrodes (A-M Systems; 50-100 $\mu \mathrm{m} ; 4-12 \mathrm{M} \Omega$ measured at $1 \mathrm{kHz}$ in vitro) were placed stereotaxically into the cell body layers or the dendritic layers of the dentate gyrus and the CA3 subfield so that evoked responses could be recorded simultaneously from these two subfields. In some experiments, single recording electrodes were glued to concentric bipolar stimulating electrodes (horizontal tip separation, 100-200 $\mu \mathrm{m}$; vertical tip separation, $500 \mu \mathrm{m}$ ) and placed such that perforant path-evoked granule cell responses could be evaluated and mossy fibers in the hilus could be excited. In general, perforant path-todentate responses and mossy fiber-to-CA $3 \mathrm{c}$ responses were evaluated for a $1 \mathrm{~mm}$ cross-section of the hippocampus, perpendicular to the long axis, roughly corresponding to the anatomically identified mossy fiber trajectory (Claiborne et al., 1986). At the completion of each experiment, recording and stimulation loci were marked by passing $100 \mu \mathrm{A}$ of current for $8-15 \mathrm{sec}$ through the metal electrodes; animals were deeply anesthetized with pentobarbital sodium and perfused transcardially with $0.9 \%$ formalin. The brains were removed and stored in $10 \%$ formalin for at least $2 \mathrm{~d}$, and frozen sections $50 \mu \mathrm{m}$ thick were taken using a sliding microtome. The sectioned tissue then was stained for metal deposits with $10 \%$ potassium ferrocyanide and counterstained with $0.2 \%$ saffranin- $O$.

In some experiments, small quantities (nanoliters per minute) of pharmacological agents were delivered with a micropressure ejection system (15 msec impulses; $5-15 \mathrm{psi} ; 1 \mathrm{psi}=6.9 \mathrm{kPa})$ into the cell body or dendritic regions.

Data collection and analysis. Stimulation pulses $(0.1-0.2 \mathrm{msec})$ were delivered by using constant low frequencies $(<0.2 \mathrm{~Hz})$ or pairs of pulses with interpulse intervals that varied between 10 and $200 \mathrm{msec}$. In cases in which two pathways were being assessed (e.g., perforant path input to the dentate and mossy fiber input to CA3), stimulation pulses were given alternately to each pathway $(0.1 \mathrm{~Hz} /$ pathway). In one series of experiments, $10-30 \mathrm{~Hz}$ stimulation ( $<30$ pulses) was delivered to the perforant path while recording in both the cell layers of the dentate gyrus and CA3. Three primary patterns of stimulation trains were tested for induction of LTP: (1) $400 \mathrm{~Hz}$ trains, 10 impulses per train, one train/10 sec; (2) 100 $\mathrm{Hz}$ trains, 50 impulses per train, one train/10 sec; and (3) $200 \mathrm{~Hz}$ bursts at a $10 \mathrm{~Hz}$ frequency (theta burst), five impulses per burst, one burst/100 msec. Unless indicated differently, a total of 100 impulses were given. In some experiments, lower frequencies of stimulation $(10-50 \mathrm{~Hz})$ were used to induce LTP. The stimulation patterns of these trains were similar to the $100 \mathrm{~Hz}$ pattern: one to two trains of 50 pulses and one train $/ 10 \mathrm{sec}$. Long-term potentiation was operationally defined as an increase in population spike amplitude $>120 \%$ of control response amplitude for a minimum of $20 \mathrm{~min}$.

Evoked field potentials were bandpass-filtered using low- and highfrequency limits of 0.003 and $10 \mathrm{kHz}$, respectively. Unitary spike events generated by single cells were recorded simultaneously and differentiated from population field potentials using low- and high-frequency limits of $0.1-1.0$ and $10 \mathrm{kHz}$, respectively. Data were digitized at $10-20 \mathrm{kHz}$ (2400/E Series data acquisition processor, Microstar Laboratories) on a Series 3500 HP-Apollo workstation and stored for later analysis.

Laminar analysis was performed by lowering a recording electrode into the dorsal hippocampus parallel to the dendritic axis of the pyramidal and granule neurons. Recordings were started in stratum oriens of $\mathrm{CA} 1$, and the electrode was lowered at increments of $50 \mu \mathrm{m}$ until either the ventral blade of the dentate gyrus or stratum oriens of CA3c was reached. The tissue was allowed to stabilize for 1-2 min at each recording site, and then three to five responses were evoked at $0.1 \mathrm{~Hz}$. Further analysis was performed on averages of the responses. In some experiments, up to three stimulation intensities were given (intensity ranged from threshold for activation of single action potentials in stratum pyramidale to intensities supramaximal for evoked field responses). Additionally, in cases in which $10 \mathrm{~Hz}$ stimulation trains were given, the intertrain interval was $1 \mathrm{~min}$. The one-dimensional current-source density (CSD) at each site $(x)$ was calculated using the following formula:

$$
I_{\mathrm{x}}=-\sigma\left(E_{\mathrm{x}-\mathrm{h}}-2 E_{\mathrm{x}}+E_{\mathrm{x}+\mathrm{h}}\right) / 4 h^{2},
$$

where $I_{\mathrm{x}}$ is the current at location $x, h$ is the sampling distance $(50 \mu \mathrm{m})$, $E_{\mathrm{x}}$ is the extracellular voltage at location $x, E_{\mathrm{x}-\mathrm{h}}$ is the extracellular voltage at location $x-h, E_{\mathrm{x}+\mathrm{h}}$ is the extracellular voltage at location $x+$ $h$, and $\sigma$ is the tissue conductivity tensor (for a complete treatment of the theoretical basis of CSD analysis, see Freeman and Nicholson, 1975). The tissue (i.e., extracellular space) was assumed to be isotropic for the pyramidal cell regions of the hippocampus.

Because the stability of brain tissue is critical for an accurate rendering of laminar profiles and calculated CSDs, basic physiological function of the animal was carefully monitored, and any aberration in breathing, heart rate, or EEG resulted in an end to the experiment.

\section{RESULTS}

\section{Frequency-dependent excitation of hippocampal granule and pyramidal neurons}

The primary excitatory afferent to hippocampus originates in layer II of the entorhinal cortex and projects monosynaptically to the dentate gyrus and the CA3 pyramidal cell region (Lorente de Nó, 1933; Steward and Scoville, 1976; Tamamaki and Nojyo, 1993; Witter, 1993). Intrinsic projections from dentate granule cells to CA3 pyramidal neurons provide an additional cascade of excitatory input (Swanson et al., 1978; Amaral and Witter, 1989). Thus, entorhinal cortical and intrinsic hippocampal afferents form the basis for a feedforward excitation of the pyramidal cell fields, such that an excitatory volley from the entorhinal cortex excites both dentate granule cells and hippocampal pyramidal cells simultaneously (Yeckel and Berger, 1995b) and subsequently induces longer latency excitation of CA3 and CA1 neurons (Yeckel and Berger, 1990, 1995b; Berger and Yeckel, 1991).

Consistent with sequential excitation through the trisynaptic pathway, latencies to population and single-cell responses were progressively longer for each of the three subfields: (1) entorhinal excitation of the dentate granule cells, 4.5-5.5 msec; (2) disynaptic excitation of CA3, 8-13 msec; and (3) trisynaptic excitation of CA1, 16-21 msec. The longer latency excitations of CA3 and CA1 neurons could not be maintained in response to continuous stimulation with frequencies $>25 \mathrm{~Hz}$ because of failure of propagation of the response across synapses, and therefore, suggests multisynaptic excitation. The latencies of pyramidal cell discharge also were consistent with the cumulative monosynaptic latencies for each of the individual pathways constituting the trisynaptic circuit: $4-6 \mathrm{msec}$ for medial perforant pathway input to granule cells, 4-7 msec for activation of CA3 by mossy fiber 

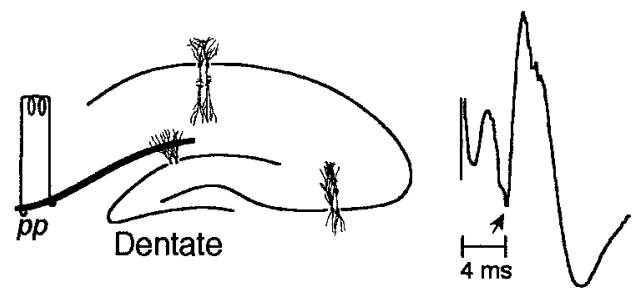

$10.4 \mathrm{mV}$
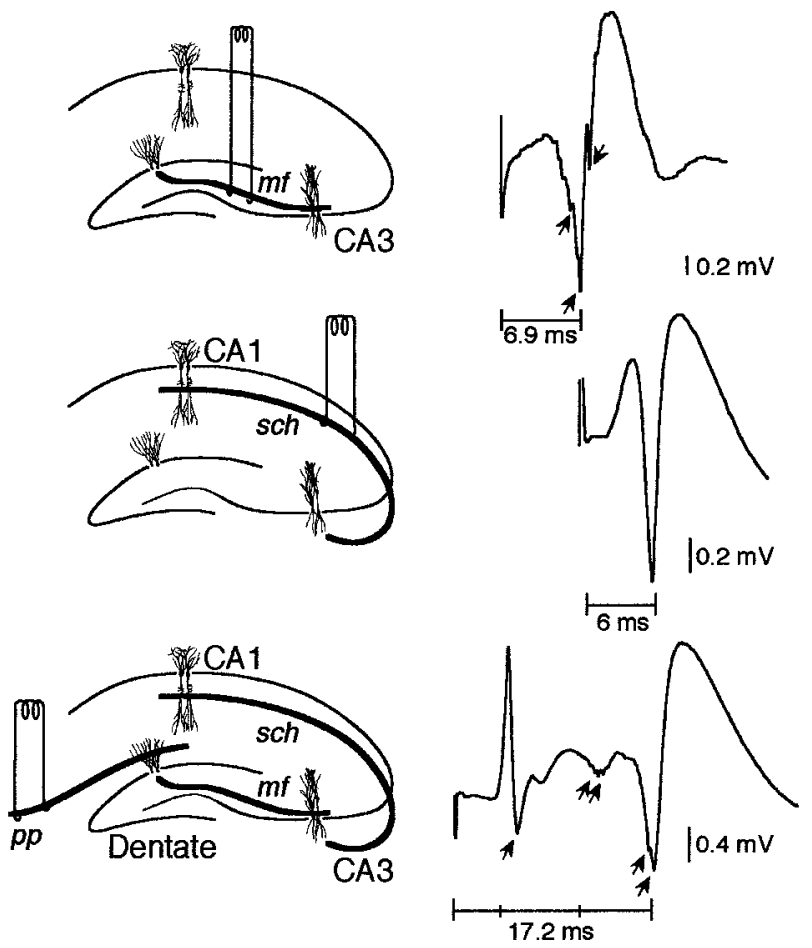

Figure 1. Serial propagation through the trisynaptic pathway. Schematic diagram of the intrinsic organization of hippocampus and associated physiological responses (data are from different preparations). Top, Entorhinal innervation of the dentate gyrus via the perforant path $(p p)$. Perforant path-evoked population spike in the dentate gyrus (arrow indicates a unitary discharge). Second from top, Mossy fiber ( $\mathrm{mf}$ ) input to the CA3 pyramidal cell region originating from dentate granule cells. Stimulation of granule cell axons evokes single units (arrows) and the associated population spike. Second from Bottom, Innervation of the CA1 pyramidal cell region by CA3 via the Schaffer collaterals (sch). Stimulation of CA3 axons within stratum radiatum of CA1 resulted in a monosynaptically evoked population spike. Bottom, Trisynaptic excitation of CA1 by $10 \mathrm{~Hz}$ stimulation of perforant path fibers. Single action potentials were excited at latencies corresponding to monosynaptic, disynaptic, and trisynaptic excitation. Disynaptic excitation of CA1 resulted from monosynaptic excitation of CA3, which in turn excited CA1 monosynaptically.

stimulation, and 5-8 msec for responses of CA1 cells evoked by Schaffer collateral stimulation. Disynaptic excitation of CA1 was consistent with monosynaptic excitation of CA3, followed by monosynaptic excitation via the Schaffer collaterals (Fig. 1). Inhibition of perforant path-evoked granule cell activity by pressure ejection of the $\mathrm{GABA}_{\mathrm{A}}$ agonist muscimol (100-500 $\left.\mu \mathrm{M}\right)$ locally into the dentate gyrus was accompanied by a suppression of long-latency responses observed in CA3 (Fig. 2). Conversely, local application of the $\mathrm{GABA}_{\mathrm{A}}$ antagonist bicuculline methiodide $(100-200 \mu \mathrm{M})$ increased granule cell responsiveness to entorhinal input and selectively increased the magnitude of longlatency CA3 responses (Yeckel and Berger, 1990; Berger and Yeckel, 1991).

On the basis of previous reports that stimulation of perforant
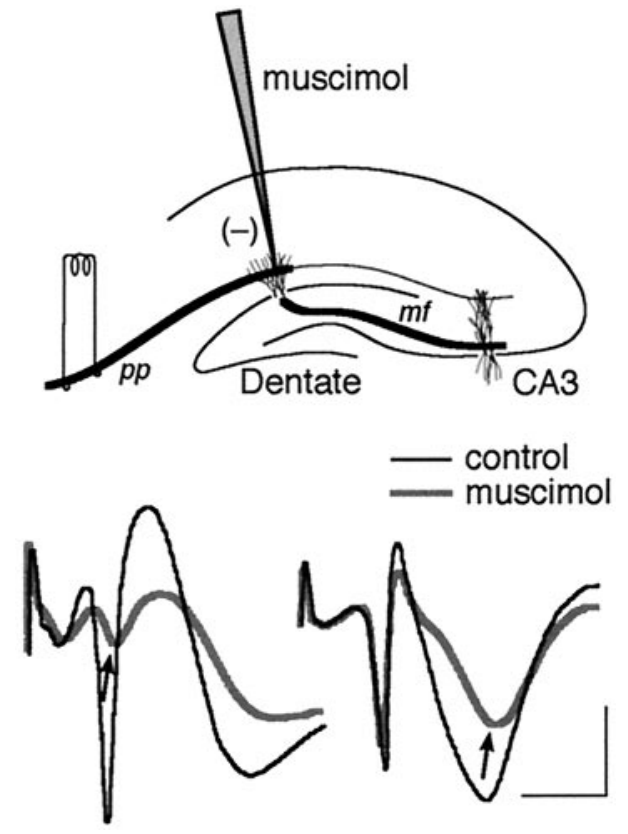

Figure 2. Characterization of disynaptically evoked responses in CA3 by stimulation of entorhinal afferents. The presence of disynaptic input to CA3, via mossy fiber $(\mathrm{mf})$ input, was confirmed by selectively altering granule cell responsiveness to perforant path $(p p)$ stimulation and observing changes in longer-latency components of CA3 field responses. Local application of the $\mathrm{GABA}_{\mathrm{A}}$ agonist muscimol (100-500 $\left.\mu \mathrm{M}\right)$ into the dentate gyrus suppressed granule cell responsiveness (arrow) to perforant path stimulation (the same stimulation intensity was used for both control and muscimol conditions) and concomitantly increased suppression of the longer-latency component of the CA3 response (arrow). Waveforms represent averages of five responses. Calibration bar, $5 \mathrm{msec}$ and $1 \mathrm{mV}$.

path fibers with frequencies of $\sim 10 \mathrm{~Hz}$ leads to a progressive recruitment in the number of active granule cells (i.e., frequency facilitation; Andersen et al., 1971; Munoz et al., 1991), and on the basis of quantitative anatomical findings that granule cell output converges substantially in its projection to CA3 (estimates as great as 12:1; Gaarskjaer, 1978; Amaral et al., 1990), we tested the hypothesis that the relative strengths of monosynaptic and multisynaptic entorhinal inputs to hippocampal pyramidal cells are frequency-dependent. Using stimulation frequencies ranging from 1 to $30 \mathrm{~Hz}$ (total number of pulses, 20-30), we found that monosynaptic excitation of pyramidal cells by perforant path fibers occurs preferentially in response to frequencies of electrical stimulation $<5 \mathrm{~Hz}$. In contrast, frequencies of $10-15 \mathrm{~Hz}$ greatly enhances polysynaptic excitation of hippocampal pyramidal neurons through the intrinsic pathways (Yeckel and Berger, 1990; Berger and Yeckel, 1991) (Fig. 3).

To resolve the propagation of excitation through the intrinsic hippocampal pathways better, CSD analysis was performed on laminar profiles of field potentials evoked by $10 \mathrm{~Hz}$ stimulation of perforant path fibers. A recording electrode was lowered into the dorsal hippocampus at increments of $50 \mu \mathrm{m}$, and three $10 \mathrm{~Hz}$ trains of 15 impulses were delivered (intertrain interval was 1 min). Evoked responses were averaged for each site, and estimates of the one-dimensional CSD were generated. The results of these experiments showed that current sinks generated by the first couple of stimulation pulses in a $10 \mathrm{~Hz}$ train were short in latency (typically $<7 \mathrm{msec}$ ), and limited to the stratum moleculare of the dentate gyrus and stratum lacunosum-moleculare of both the CA3 and CA1 subfields. Additional stimulation pulses in a $10 \mathrm{~Hz}$ 


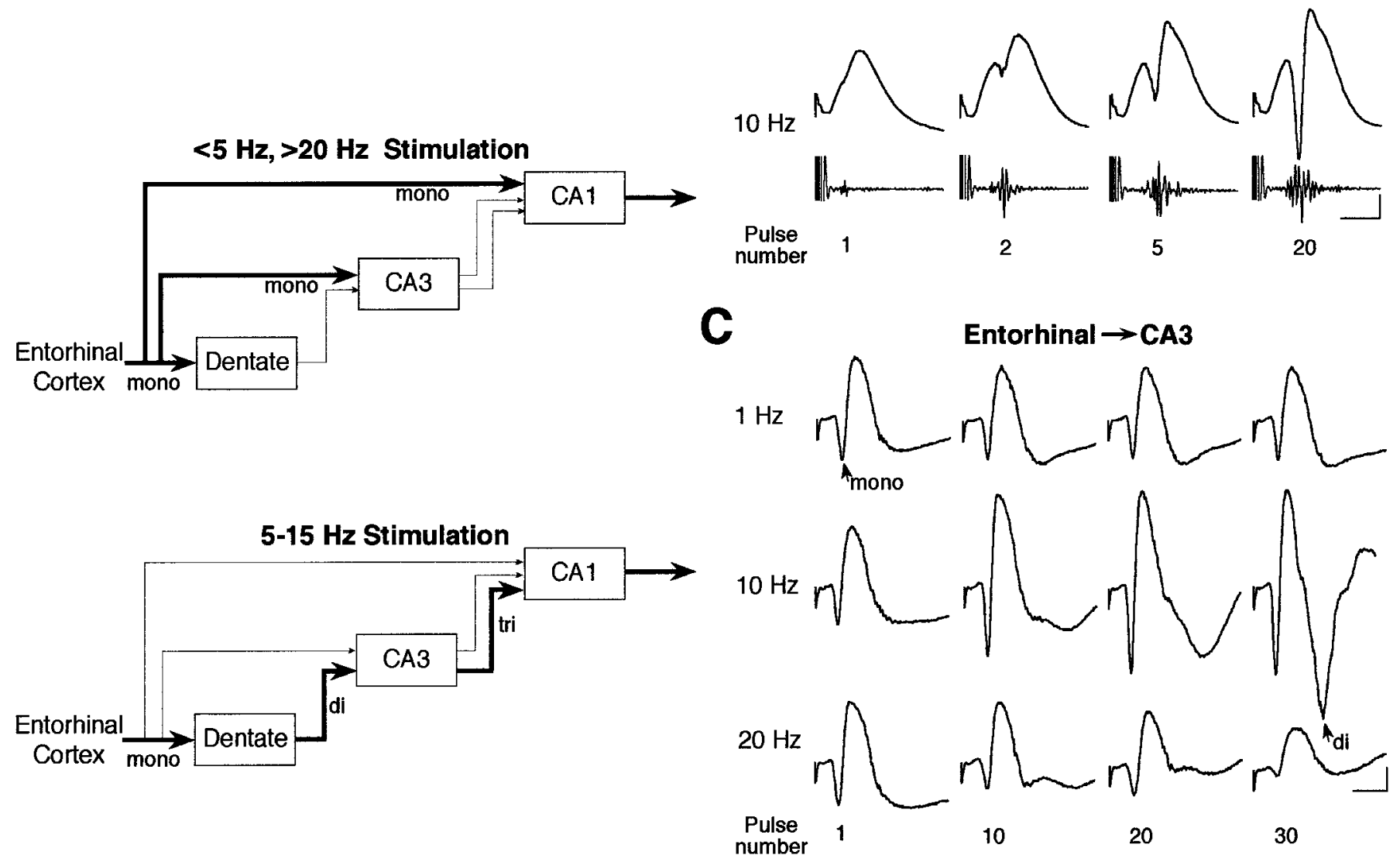

Figure 3. A, Diagrammatic representation of the relative strengths of monosynaptic and polysynaptic excitation of the pyramidal cell regions as a function of the frequency of entorhinal input. Top, Stimulation frequencies $<5$ or $>20 \mathrm{~Hz}$ result predominantly in monosynaptic activation of CA3 and CA1 pyramidal neurons. Bottom, Stimulation frequencies between 5 and $15 \mathrm{~Hz}$ result in enhanced excitation of pyramidal cells transsynaptically. B, Frequency-dependent excitation of dentate granule cells. Recruitment of granule cell activity with $10 \mathrm{~Hz}$ stimulation of entorhinal afferents. Population field responses (top) and multiunit recordings (bottom) recorded from the granule cell layer of the dentate gyrus show progressive facilitation of evoked responses during a $10 \mathrm{~Hz}$ stimulation train (20-30 impulses). Facilitation was observed only during the stimulation train. Calibration bar, $50 \mu \mathrm{V}$ and 1 $\mathrm{mV}$ for units and fields, respectively, and $5 \mathrm{msec}$. $C$, Frequency-dependent disynaptic excitation of hippocampal CA3 pyramidal cells. Trains of stimulation were given at frequencies of 1,10 , and $20 \mathrm{~Hz}$ (30 impulses total) to perforant path fibers. Frequency-dependent excitation of direct perforant path input to CA3 (similar to facilitation of perforant path-to-dentate responses above) and indirect (i.e., disynaptic) input via the mossy fiber projection (arrows identify monosynaptically and disynaptically evoked population spikes). Calibration bar, $1 \mathrm{mV}$ and $5 \mathrm{msec}$.

train resulted in disynaptic and trisynaptic excitation of the pyramidal cell regions via the trisynaptic pathway, as evidenced by longer-latency current sinks $(12-18 \mathrm{msec})$ in stratum lucidum of the CA 3 subfield and stratum radiatum of the CA1 subfield (Fig. 4). These findings reveal that the magnitude of disynaptic and trisynaptic excitatory input to CA 3 and CA 1 pyramidal neurons is predominantly determined by the frequency of perforant path input, with $10-15 \mathrm{~Hz}$ resulting in the maximum excitation.

\section{Frequency-dependent induction of perforant path and mossy fiber LTP}

We next examined the relationship between frequency of afferent stimulation and the probability and magnitude of LTP induction of monosynaptic, perforant path input to dentate granule cells and monosynaptic, mossy fiber input to CA3 pyramidal cells. Field potentials evoked in CA3, in vivo, have not been characterized adequately, however, so it was first necessary to establish criteria for identification of monosynaptically evoked mossy fiber responses (Yeckel and Berger, 1995a; Berger et al., 1997).

Distinguishing CA3 responses to mossy fiber excitation versus other afferents is technically difficult and is an issue that remains controversial (Williams and Johnston, 1991; Claiborne et al., 1993; Langdon et al., 1993). Pyramidal neurons of CA3 receive four major sets of synaptic input: monosynaptic perforant path input, mossy fiber input, innervation by other CA3 pyramidal neurons via recurrent collaterals, and inhibitory input from GABAergic interneurons local to the CA3 subfield. In addition to criteria such as the presence of orthodromic, short-latency unitary discharges in stratum pyramidale of CA3, laminar and CSD analyses were used to identify stratum lucidum as the location for short-latency current sinks generated in response to hilar stimulation and to distinguish these mossy fiber-evoked responses from other afferents such as the recurrent collaterals.

Although recordings were made from the CA3c region (proximal to the dentate gyrus) - a subregion of CA3 with a lower density of recurrent innervation than has been reported for the CA3a and CA3b subfields (Lorente de Nó, 1933; Ishizuka et al., 1990) — we still found considerable contamination of monosynaptically evoked mossy fiber field responses by polysynaptic activation via the recurrent collaterals. The difficulty of interpreting CA3 field responses evoked by stimulating presumed mossy fibers 


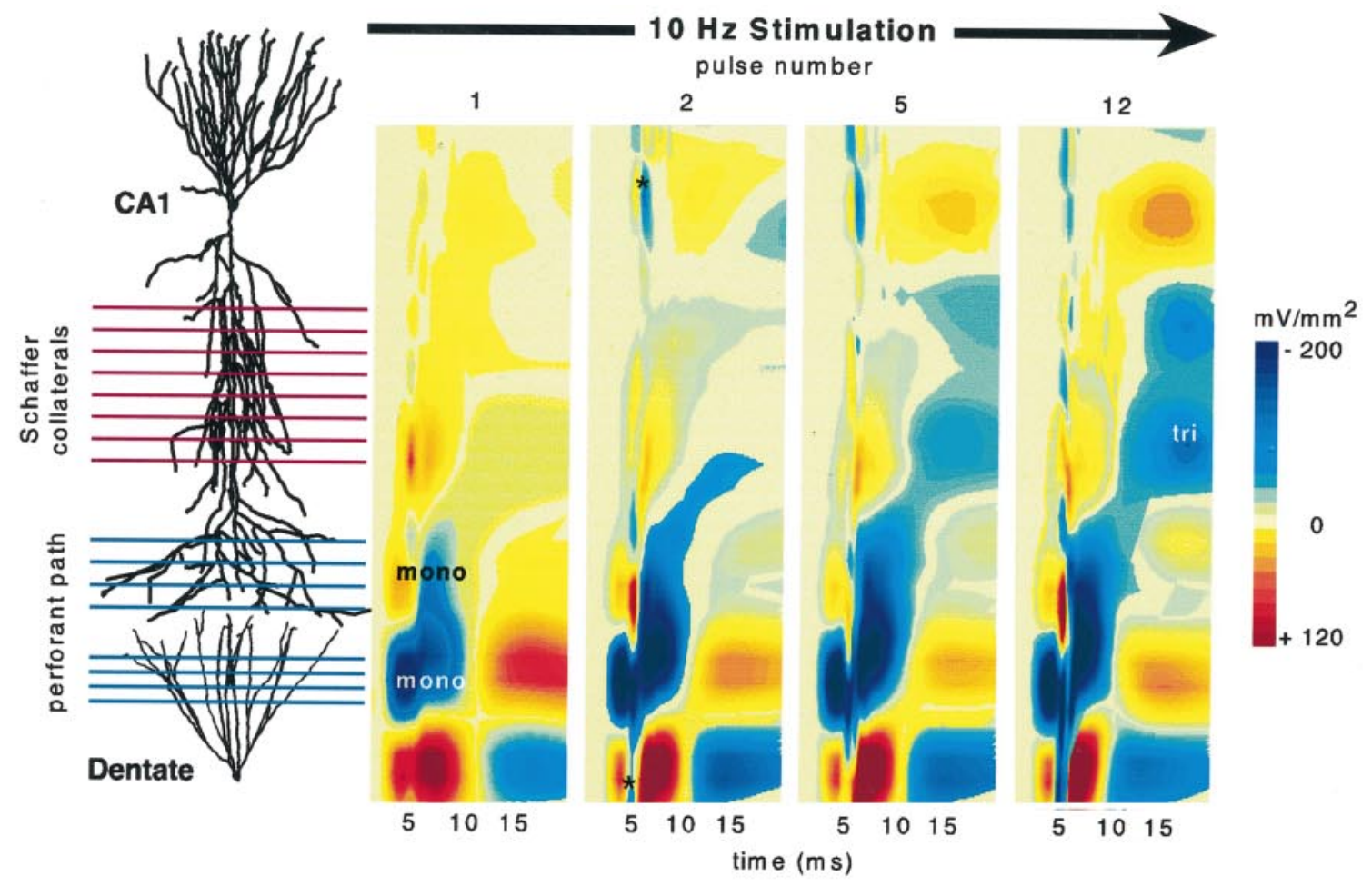

A

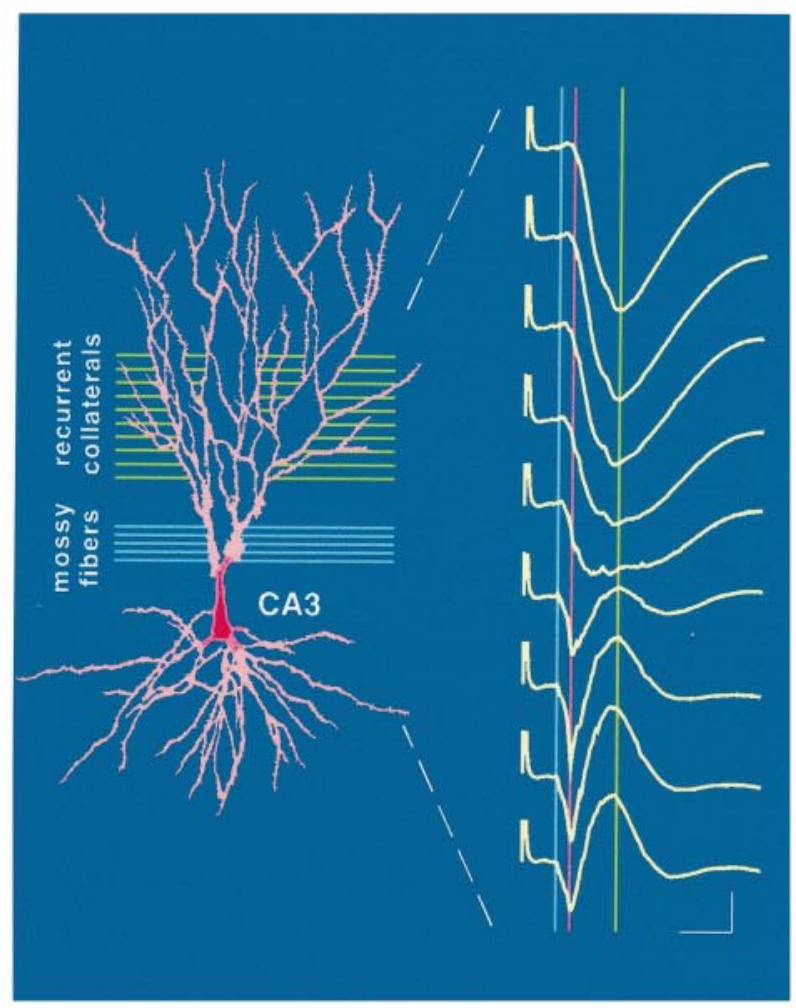

B

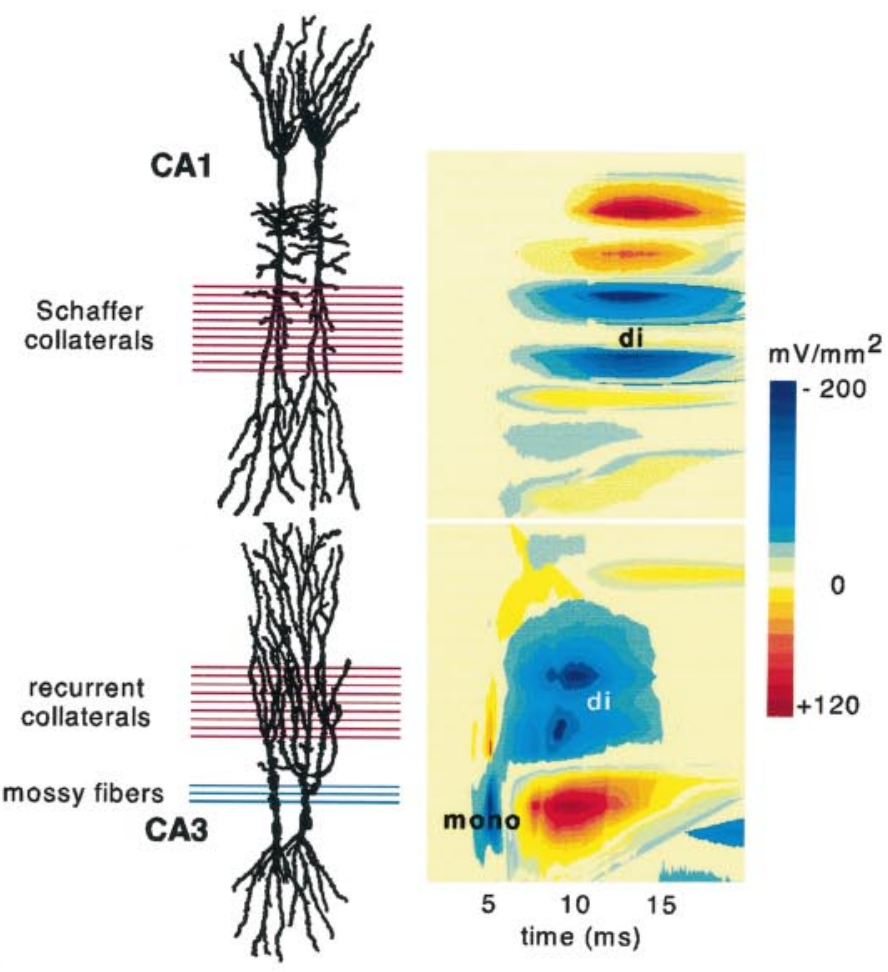


in the hilus (i.e., distinguishing the onset and slope of monosynaptic mossy fiber activation from that of population EPSPs evoked by recurrent collaterals) is apparent with laminar analysis of field potentials and estimations of one-dimensional CSDs $(n=5)$. The results of laminar analysis showed that mossy fiber-evoked population EPSPs recorded in stratum lucidum of CA3 were often irregular in appearance because of the presence of numerous single action potentials generated in nearby stratum pyramidale of CA3 ( $<75 \mu \mathrm{m}$ away). Although relatively low stimulation intensities were used, we were not able to evoke a population EPSP subthreshold for generation of single action potentials in stratum pyramidale of CA3 that was detectable above background noise (Fig. 5A). Similarly, the proximity of evoked synaptic responses to associated action potential generation made it difficult to resolve population spikes recorded in stratum pyramidale from population EPSPs generated in stratum lucidum. In contrast, field responses recorded in stratum radiatum, reflecting disynaptic excitation by recurrent collaterals, were smooth in appearance, similar to population EPSPs recorded in stratum moleculare of the dentate gyrus or population EPSPs recorded in stratum radiatum of CA1. Current-source density analysis confirmed stratum lucidum and stratum pyramidale as the locations for shortlatency current sinks generated in response to hilar stimulation and showed a longer-latency current sink in stratum radiatum (and corresponding current source in stratum pyramidale) generated by disynaptic recurrent excitation (Fig. $5 B$ ).

Although field potentials recorded in stratum pyramidale represent a composite of the population spike and the population EPSP, isolation of monosynaptically evoked mossy fiber responses was performed most accurately by recording in stratum pyramidale, where contamination attributable to disynaptic excitation via the recurrents occurred later in time and, as source current, could be distinguished more easily from the current sink generated by monosynaptic mossy fiber excitation. Mossy fiberevoked responses were quantified by measuring the amplitude of the negative peak of the short-latency component of the response.

As we have shown previously (Berger and Yeckel, 1991), and as has been confirmed by others (Derrick and Martinez, 1994), highfrequency stimulation $(>100 \mathrm{~Hz})$ is less optimal for inducing mossy fiber LTP. As shown in Figure 6, comparison of the effects of 100 and $400 \mathrm{~Hz}$ stimulation (50-100 impulses) revealed that $100 \mathrm{~Hz}$ was significantly more efficient at inducing mossy fiber LTP than $400 \mathrm{~Hz}$ tetanization, both in terms of probability of induction and magnitude of potentiation ( $n=5$ for each frequency; unpaired $t$ test, $p<0.001$ ). This is in contrast to perforant path input to the dentate $(n=5$ for each frequency), in which the probability of induction and magnitude of potentiation were not significantly different when 100 and $400 \mathrm{~Hz}$ frequencies were used to induce LTP (Fig. 6A). Additional experiments revealed that the probability of inducing mossy fiber LTP was significantly greater for stimulation frequencies of 10-50 $\mathrm{Hz}$ (50-100 pulses total) than for higher frequencies of $100-400 \mathrm{~Hz}$ (67 and 33\%, respectively); the opposite trend was found for the probability of LTP induction of the dentate gyrus $(>100 \mathrm{~Hz}, 80 \%$; $<25 \mathrm{~Hz}, 25 \%$ ). Consistent with previous reports, it also was found that stimulation frequencies as low as $10 \mathrm{~Hz}$ were capable of inducing mossy fiber LTP (Zalutsky and Nicoll, 1990), whereas the lowest frequency capable of inducing perforant path LTP was $25 \mathrm{~Hz}$ (Fig. $6 B)$.

The difference in optimal stimulation parameters for LTP induction of perforant path and mossy fiber synapses may reflect the known differences in the cellular mechanisms underlying potentiation of the two pathways (Harris and Cotman, 1986; Wigstrom et al., 1986). Application of the NMDA receptor antagonist D-APV $(50-100 \mu \mathrm{M})$ blocked the induction of perforant path LTP (12 of 12 experiments, $400 \mathrm{~Hz}$ ); recovery occurred 20-40 min after D-APV administration, as assessed by the ability to induce LTP $(n=4)$. This is in contrast to LTP of mossy fiber input to CA3, in which LTP was induced despite pressure ejection of D-APV $(50-100 \mu \mathrm{M})$ into the CA3 subfield (6 of 15 experiments, $100 \mathrm{~Hz}$ stimulation trains used). The lack of NMDA receptor dependence for mossy fiber LTP confirms the interpretation that responses evoked in CA3 by hilar stimulation represent excitation of mossy fibers and not inadvertent activation of perforant path or Schaffer collaterals, for which LTP induction is NMDA receptor-dependent (Fig. 6C).

\section{Transsynaptic induction of mossy fiber LTP after stimulation of perforant path}

The experiments presented thus far demonstrate that $10 \mathrm{~Hz}$ stimulation of entorhinal afferents greatly enhances disynaptic excitation of CA3 pyramidal cells, and that comparable stimulation frequencies are capable of inducing LTP of mossy fiber input to CA3 cells. These findings suggest that when entorhinal activity approaches this frequency range, there may be sufficient recruitment of granule cell output to CA3 to reach the critical level of excitation required for induction of LTP at mossy fiber synapses. We tested this hypothesis by investigating whether $10-15 \mathrm{~Hz}$ stimulation of perforant path fibers was capable of inducing LTP of mossy fiber input to CA3 transsynaptically via monosynaptic excitation of the dentate gyrus and disynaptic excitation of CA3. In one

\footnotetext{
$\leftarrow$

Figure 4. Top. Transsynaptic excitation of CA1 pyramidal cells with $10 \mathrm{~Hz}$ stimulation. Contour plots of one-dimensional CSDs computed from field responses evoked by $10 \mathrm{~Hz}$ stimulation of perforant path fibers. Each panel shows the spatial and temporal distribution of current sinks (- values) and current sources (+ values) for a given impulse in the stimulation train (impulse number listed above the plot). The presence of short-latency current sinks in the distal dendritic region of CA1 and the middle- to outer-third of dentate granule cells is consistent with monosynaptic excitation by entorhinal afferents (mono; monosynaptically evoked population discharges are identified with an asterisk). A longer-latency current sink, present in stratum radiatum of CA1, is consistent with trisynaptic excitation of CA1 via Schaffer collaterals (tri).

Figure 5. Bottom. Laminar analyses of mossy fiber-evoked responses in CA3. Data show the difficulty in distinguishing monosynaptic and polysynaptic responses evoked by stimulation of mossy fiber axons in the hilus. $A$, Laminar profile of field potentials recorded from the proximal two-thirds of the CA3c subfield (the region bound by the white dashed lines) while stimulating mossy fibers in the hilus. Vertical lines identify various components of the waveform: (1) the line on the left (blue) shows the onset of the mossy fiber-evoked population EPSP; (2) the middle line (red) identifies the latency for activation of the population spike (and contamination of the population EPSP recorded in the dendrites); (3) the line on the right (green) shows the latency to peak of disynaptic activation of CA3 via the recurrent collaterals. Waveforms are averages of five responses recorded at $50 \mu \mathrm{m}$ increments. Calibration bar, $0.6 \mathrm{mV}$ and $5 \mathrm{msec}$. B, Current-source density representation of mossy fiber excitation. Contour plot of one-dimensional CSD identifies the spatial and temporal distribution of current sinks ( - values) and current sources (+ values). The presence of a short-latency current sink in stratum lucidum of CA3 (proximal apical dendrites) is consistent with monosynaptic excitation (mono) by mossy fiber input. Longer-latency current sinks, present in stratum radiatum of CA3 and CA1, are consistent with disynaptic excitation (di) via the recurrent collaterals and Schaffer collaterals, respectively.
} 
Mossy Fiber $\rightarrow$ CA3
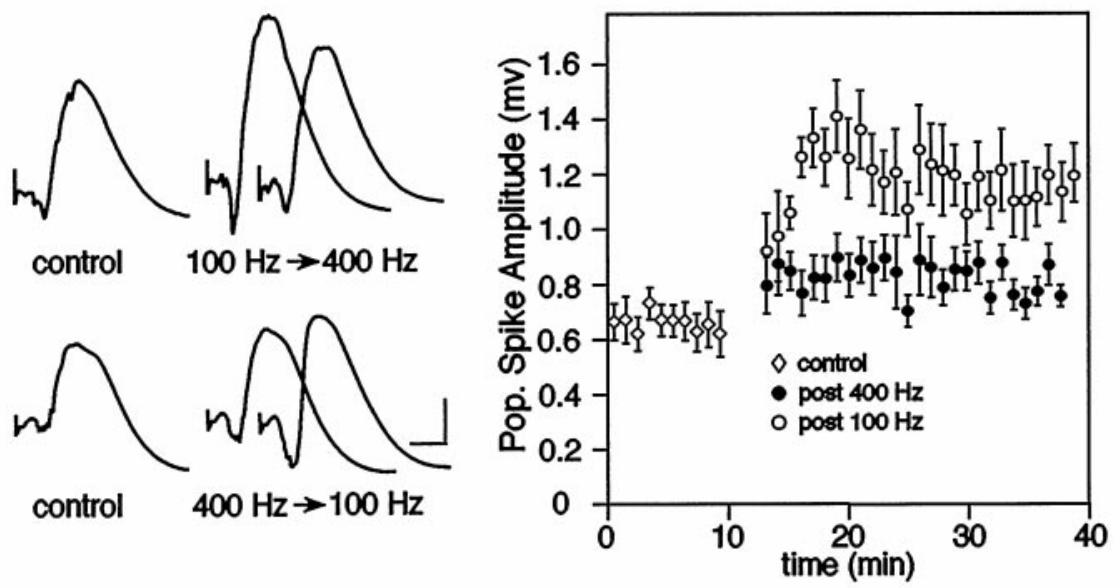

Perforant Path $\rightarrow$ Dentate

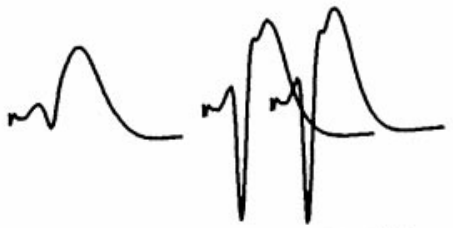

control
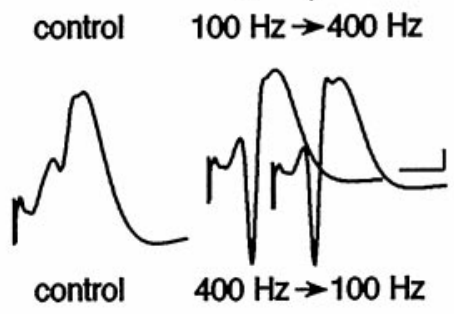

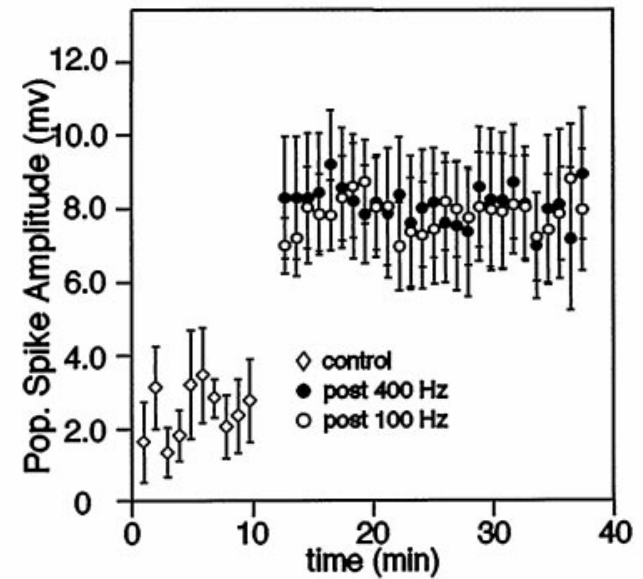

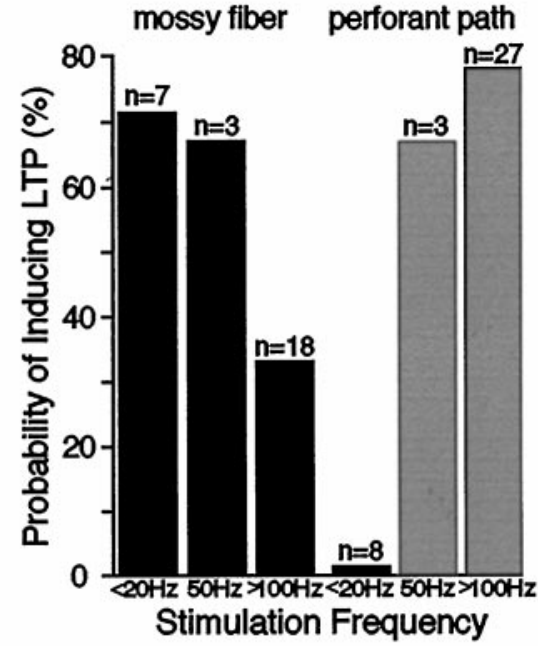

C mossy fiber perforant path

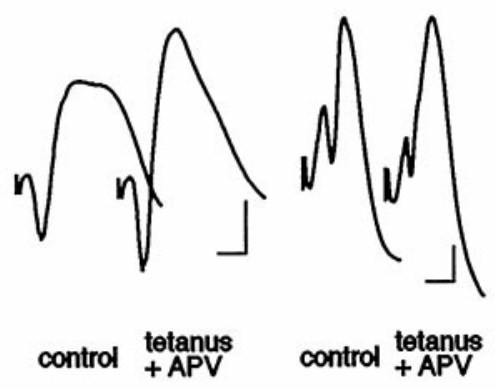

Figure 6. Optimal stimulation patterns differ for induction of perforant path and mossy fiber LTP. $A$, Data from representative experiments (left) in which $100 \mathrm{~Hz}$ stimulation (or $400 \mathrm{~Hz}$ ) was given to either the mossy fiber pathway or the perforant path, followed by $400 \mathrm{~Hz}$ stimulation (or $100 \mathrm{~Hz}$ ). Regardless of the order in which the two different stimulation frequencies were delivered to mossy fibers, $100 \mathrm{~Hz}$ stimulation induced a greater-magnitude LTP than $400 \mathrm{~Hz}$ stimulation. Group data (right) show that the $100 \mathrm{~Hz}$ stimulation protocol induces significantly greater-magnitude mossy fiber LTP than the $400 \mathrm{~Hz}$ stimulation protocol (top); similar differences were not found for 100 and $400 \mathrm{~Hz}$ stimulation of perforant path fibers (bottom) (waveforms are averages of five responses). Calibration bar, $1 \mathrm{mV}$ and $5 \mathrm{msec}$. Graphs summarize results from five experiments for each stimulation frequency. Error bars indicate SEM. $B$, The probability of inducing mossy fiber LTP was significantly greater for lower stimulation frequencies $(<50 \mathrm{~Hz})$ than for higher $(>100 \mathrm{~Hz})$ frequencies. In contrast, there was a greater probability of inducing LTP of perforant path input at higher frequencies of stimulation $(>50$ $\mathrm{Hz}$; LTP was never induced for perforant path input with stimulation frequencies $<25 \mathrm{~Hz}$ ). $C$, LTP of mossy fiber input to CA3 is NMDA receptor-independent. Pressure ejection of the NMDA antagonist D-APV (50-100 $\mu \mathrm{M} ; 70 \mathrm{nl} / \mathrm{min}$ for 15-30 min) into the apical dendrites of CA3 and dentate granule cells resulted in the selective blockade of perforant path LTP (for both monosynaptic input to CA3 and the dentate gyrus; dentate population spikes shown here) but not mossy fiber LTP (waveforms represent averages of five responses). Calibration bar, $1 \mathrm{mV}$ and $5 \mathrm{msec}$.

series of experiments, stimulating electrodes were placed both in the perforant path and in the hilus of the dentate gyrus to activate mossy fiber axons of granule cells; the possibility of mossy fiber LTP was assessed by examining CA3 responses evoked by hilar stimulation before and after stimulating the perforant path with $10-15$ or $400 \mathrm{~Hz}$ (Fig. 7). In support of our hypothesis, results revealed that $10-15 \mathrm{~Hz}$ stimulation (50-100 impulses) of entorhinal cortical axons induced LTP of mossy fiber input to CA3 transsynaptically via the dentate gyrus $(n=6$; paired $t$ test, $p<$ 0.01). LTP was not induced transsynaptically when $400 \mathrm{~Hz}$ stimulation was used (eight of eight experiments). As described previously, stimulation frequencies $<25 \mathrm{~Hz}$ did not induce LTP of perforant path input to the dentate gyrus (see Fig. 6B). These data indicate that long-lasting synaptic potentiation occurs preferentially within different subregions of hippocampus depending on the frequency of entorhinal cortical input, and that potentiation can occur selectively for transsynaptically activated synapses.

\section{Modulation of transsynaptic LTP}

Results of the previous experiments predict that the probability of entorhinal cortical input inducing LTP will depend in part on the level of synaptic potentiation at the time of that input. Partial support for this prediction was obtained from experiments in which polysynaptic responses were recorded from CA3 pyramidal 

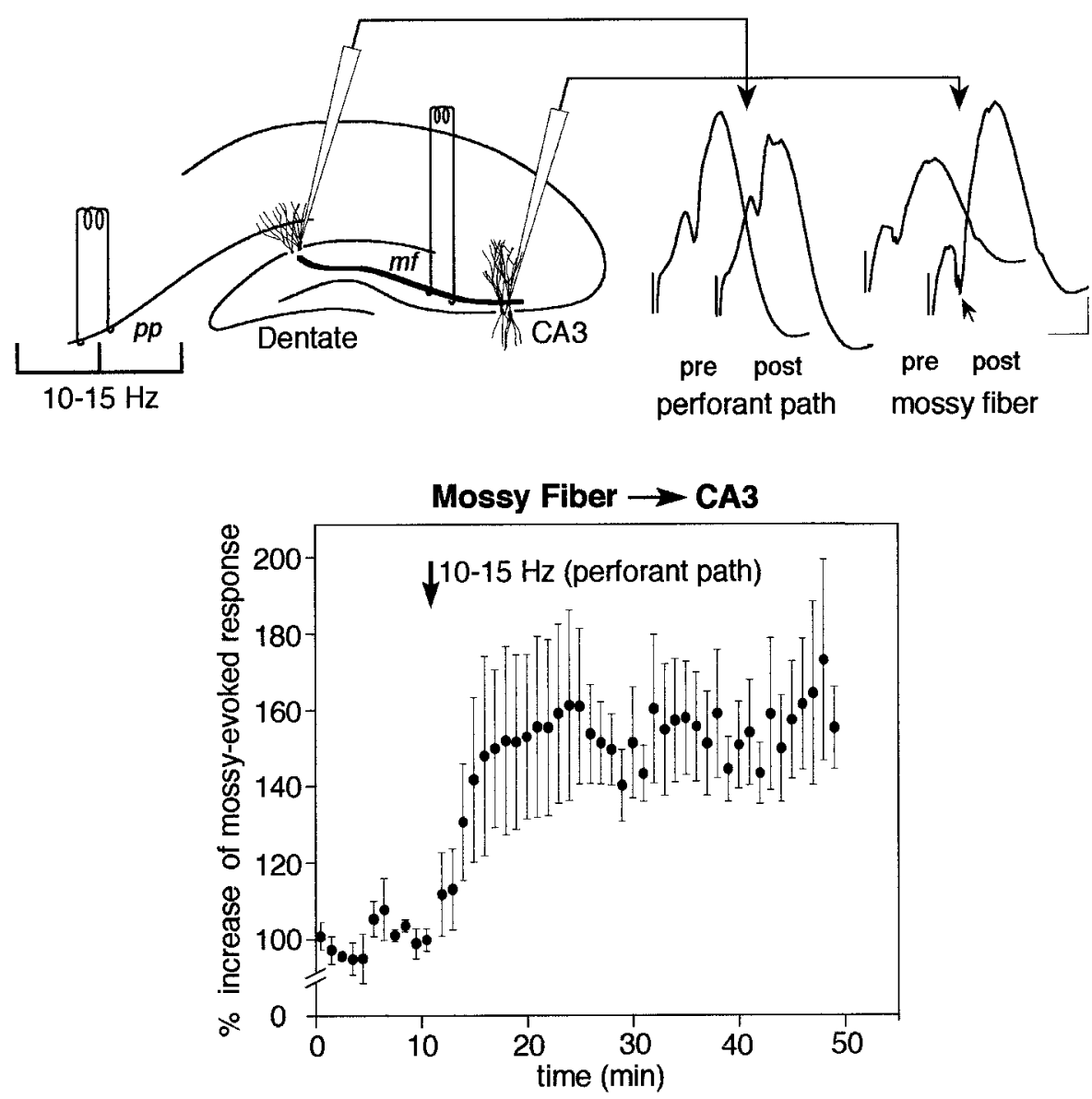

Figure 7. Transsynaptic induction of mossy fiber LTP with $10-15 \mathrm{~Hz}$ stimulation of entorhinal afferents. Top, Schematic of experimental procedure: (1) baseline recordings were obtained by stimulating, alternately, the perforant path $(p p)$ and recording evoked dentate population spikes (right, pre) and mossy fibers ( $m f$ ) while recording evoked CA3 pyramidal cell responses ( far right, pre); (2) stimulating the perforant path at a low frequency (10-15 Hz; 50-100 impulses); and (3) repeating part 1 to determine whether there was a change in the magnitude of evoked responses (post). Stimulation of perforant path fibers at $10-15 \mathrm{~Hz}$ resulted in LTP of mossy fiber input to CA3 transsynaptically via monosynaptic excitation of the dentate gyrus and disynaptic excitation of CA3. Direct, monosynaptic input to the dentate gyrus never exhibited LTP with lowfrequency stimulation trains (waveforms represent averages of five waveforms). Calibration bar, $1 \mathrm{mV}$ and $5 \mathrm{msec}$. Bottom, Summary plot of experiments in which transsynaptic LTP of mossy fiber input was induced with lowfrequency stimulation of perforant path fibers $(n=6)$. Error bars indicate SEM. neurons after monosynaptic LTP of perforant path axons. Results showed that increasing the synaptic strength of monosynaptic entorhinal afferents significantly decreased the number of impulses necessary to evoke suprathreshold disynaptic and trisynaptic responses of CA3 and CA1 and significantly increased the maximum amplitude of the evoked polysynaptic response (Berger and Yeckel, 1991). Changes in propagation through the hippocampus during $10-15 \mathrm{~Hz}$ frequency trains was examined by computing the integrated area of the long-latency component of CA3 potentials both before and after LTP of perforant path input with $400 \mathrm{~Hz}$ stimulation. The region of the evoked response corresponded to previously identified disynaptic activation (see Fig. 2). Results showed that LTP of perforant path input significantly changed propagation to CA3 (Fig. 8); polysynaptic activation increased in 8 of 11 experiments in which LTP was induced (one-way repeated measures ANOVA, $F=5.532 ; p<0.05$ ). Two experiments were excluded from analysis because of interictal bursting that occurred during and after the stimulation trains.

These data suggest that potentiation of perforant path/dentate synapses will increase the likelihood of transsynaptic LTP induction of mossy fiber input to CA3 pyramidal cells. This hypothesis was tested by first stimulating perforant path fibers at a low frequency (10-15 Hz, 50-100 impulses) and with stimulation intensities subthreshold for transsynaptic induction of mossy fiber LTP (i.e., very little disynaptic activation of CA3 was evident during the stimulation train). After induction of monosynaptic LTP of perforant path input with $400 \mathrm{~Hz}$ stimulation, the identical low-frequency, low-intensity stimulation parameters resulted in significantly greater disynaptic excitation of CA3 during the stimulation train, and consequently, transsynaptic LTP of mossy fiber input ( $n=5$; one-way repeated measures ANOVA, $F=$ 7.656; $p<0.01$, using Gieser-Greenhouse correction for repeated measures) (Fig. 9).

\section{Multisynaptic induction of hippocampal LTP with theta-patterned stimulation}

The selective induction of perforant path and mossy fiber LTP with high- and low-frequency inputs, respectively, strongly suggests that input signals incorporating induction parameters optimal for both pathways will potentiate both populations of synapses. To test this possibility, perforant path fibers were stimulated with high-frequency "bursts" of impulses (each burst consisted of five pulses delivered at $200 \mathrm{~Hz}$ ), applied at a low frequency (interburst intervals of $100 \mathrm{msec}$ ), a pattern of activity observed in layer II of the entorhinal cortex during behaviors associated with theta rhythm generation (Alonso and GarciaAustt, 1987), and shown previously to induce NMDA receptordependent LTP maximally (Larson and Lynch, 1986; Rose and Dunwiddie, 1986). The high frequency of activity within bursts is optimal for LTP of the perforant path; the lower frequency characterized by the interburst interval is optimal for LTP of mossy fibers. Stimulating the perforant path with this thetapatterned input (theta burst) resulted in the induction of LTP both monosynaptically for perforant path input to dentate and transsynaptically for mossy fiber input to CA3 ( $n=5$; two-way repeated measures ANOVA, $F=67.393 ; p<0.001$ ) (Fig. 10). In additional experiments it was found that giving theta burst stimulation at a lower intensity, or with fewer bursts $(<20)$, could 


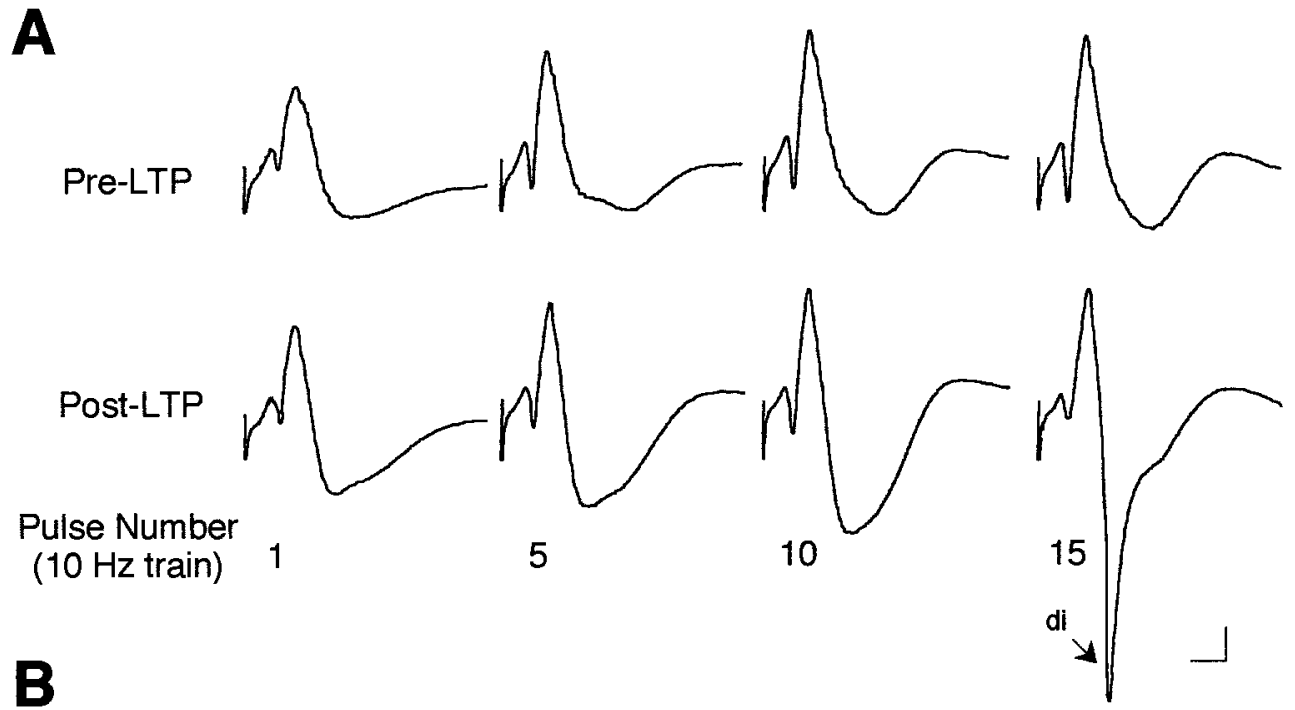

Figure 8. Propagation of excitation to pyramidal cells after LTP of entorhinal afferents. $A$, Disynaptic responses were evoked in CA3 with $10 \mathrm{~Hz}$ stimulation of entorhinal afferents ( 30 pulses total). After induction of perforant path-todentate LTP (data not shown), propagation to CA3 increased based on the size of the late component [disynaptic (di)] of the evoked response (waveforms are single evoked responses recorded during a $10 \mathrm{~Hz}$ stimulation train). Calibration bar, $0.4 \mathrm{mV}$ and $4 \mathrm{msec}$. $B$, Disynaptic propagation to CA3 increased significantly after perforant path LTP ( post pp $L T P$ ), as assessed by the integrated area of longer-latency responses corresponding to disynaptic excitation $(n=9)$. Error bars indicate SEM.

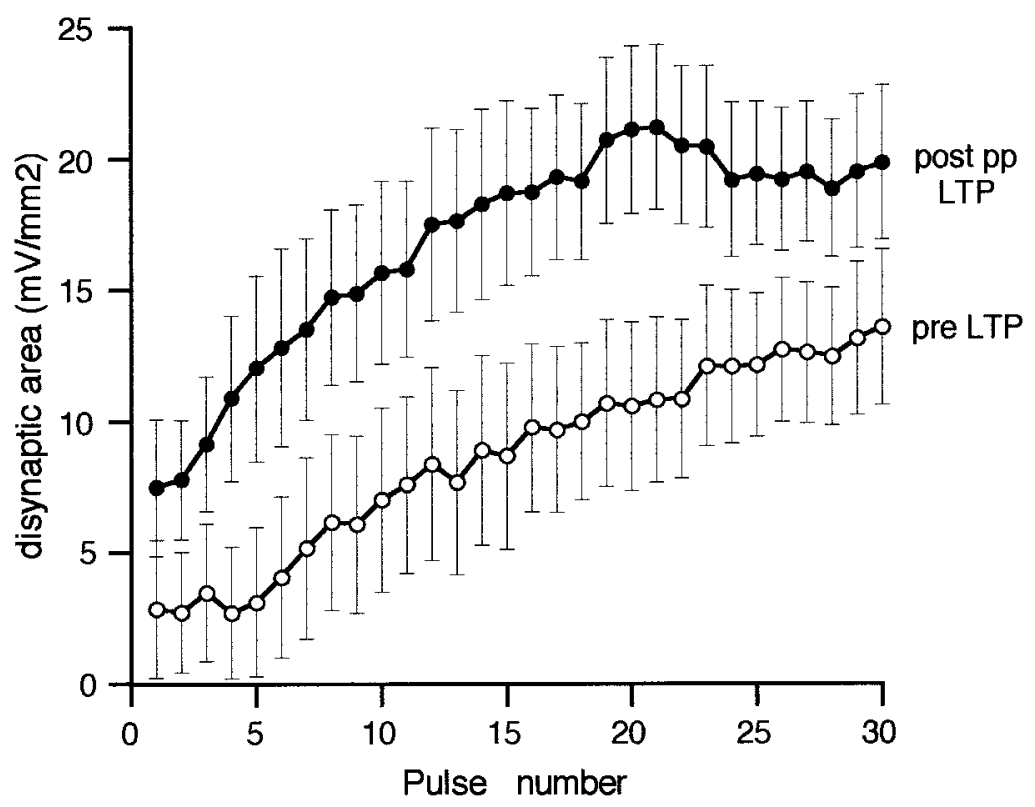

result in monosynaptic LTP but not transsynaptic LTP. After monosynaptic perforant path LTP, however, it was found that giving the identical theta burst stimulation (previously subthreshold for induction of transsynaptic LTP) could induce LTP transsynaptically for mossy fiber input to CA3 $(n=4)$. LTP induced by theta burst stimulation was NMDA receptor-dependent for perforant path input but not for LTP of transsynaptic input to CA3, as assessed by the application of D-APV $(n=2)$; this again confirmed that transsynaptic LTP occurred via the mossy fiber projection (Fig. 11).

\section{DISCUSSION}

In the studies reported here, we tested the hypothesis that different patterns of activity within the same population of entorhinal cortical afferents could lead to a selective potentiation of spatially distinct populations of synapses within hippocampus, including those activated transsynaptically. We focused specifically on potentiation of direct, monosynaptic entorhinal input to dentate granule cells, which expresses an NMDA receptor-dependent LTP, and on potentiation of indirect, disynaptic entorhinal input to CA3 pyramidal cells, which is transmitted by the mossy fiber projection of dentate granule cells and expresses an NMDA receptor-independent LTP. The principal findings of these experiments are as follows: (1) the stimulus prerequisites for the induction of LTP differ for entorhinal afferents to the dentate gyrus and mossy fiber afferents to CA3, such that higher stimulation frequencies $(>100 \mathrm{~Hz})$ are more effective at inducing LTP of perforant path input to granule cells of the dentate, and lower stimulation frequencies $(<100 \mathrm{~Hz})$ induce monosynaptic mossy fiber LTP of CA3 pyramidal cells more efficiently; (2) consistent with the findings that propagation of activity through the trisynaptic pathway predominantly results from electrical stimulation of entorhinal afferents at $10-15 \mathrm{~Hz}$, and that mossy fiber LTP can be induced with stimulation frequencies as low as $10 \mathrm{~Hz}$, we found that low frequencies of activity of entorhinal cortical axons $(10-20 \mathrm{~Hz})$ induces transsynaptic LTP of dentate granule cell mossy fiber input to CA3 selectively; (3) patterns of stimulation that mimic neuronal firing in the entorhinal cortex during endogenous theta rhythm induce LTP both monosynaptically for input 


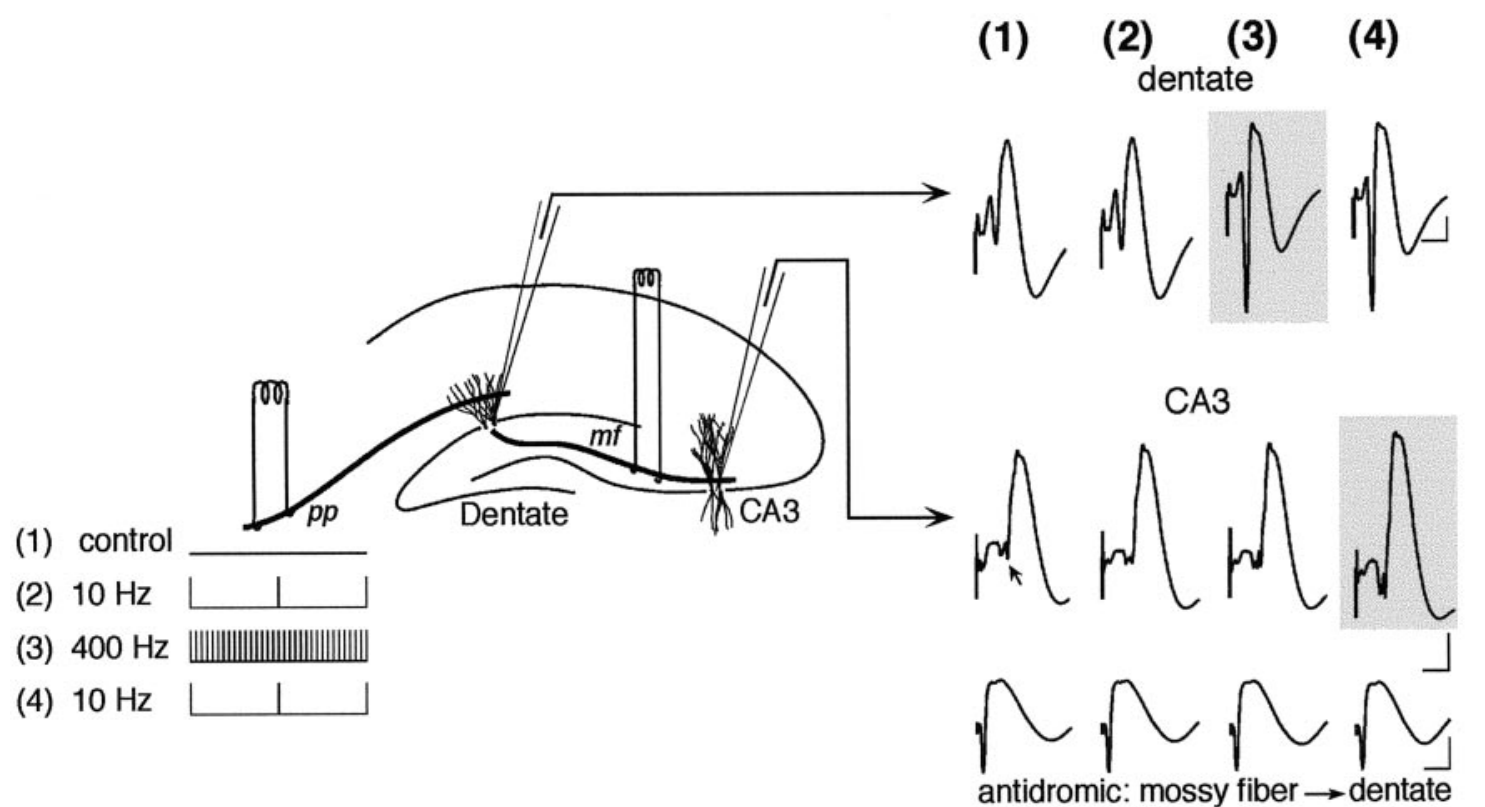

Figure 9. Induction of transsynaptic mossy fiber LTP is enabled by previous induction of perforant path LTP. Top, Schematic of stimulation paradigm: (1), alternate stimulation of the perforant path ( $p p)$ and mossy fiber $(m f)$ path while recording in the dentate and CA3, respectively; (2), evoked responses after low-frequency stimulation $(10-15 \mathrm{~Hz}, 50-100$ impulses) of perforant path fibers at intensities subthreshold for induction of transsynaptic mossy fiber LTP; (3), high-frequency stimulation (400 $\mathrm{Hz}, 50-100$ impulses) of perforant path fibers resulted in LTP of the dentate gyrus but not mossy fiber input to CA3; (4), propagation through the trisynaptic pathway was sufficiently enhanced after induction of perforant path LTP so that low-frequency stimulation [identical to that delivered in (1)] induced mossy fiber LTP transsynaptically. Antidromic activation of dentate granule cells was not effected. Arrows point to examples of mossy fiber-evoked single units. Bottom, Summary data $(n=$ 5) Error bars indicate SEM.

to dentate granule cells and transsynaptically for mossy fiber input to CA3; and (4) the ability to induce transsynaptic LTP of mossy fiber input to CA3 with stimulation of entorhinal afferents using either low-frequency or theta burst stimulation depends on the synaptic strength of monosynaptic input to the dentate, such that LTP of perforant path synapses increases the likelihood of transsynaptic induction of mossy fiber LTP.

The results of these experiments show that in the intact hippocampus, the constraints on perforant path and mossy fiber LTP induction imposed by differences at the cellular/molecular level interact with additional constraints imposed by other properties of the network in which those synapses are embedded. Both perforant path and mossy fiber synapses require a critical level of excitatory input from the entorhinal cortex, either monosynaptically or trans-

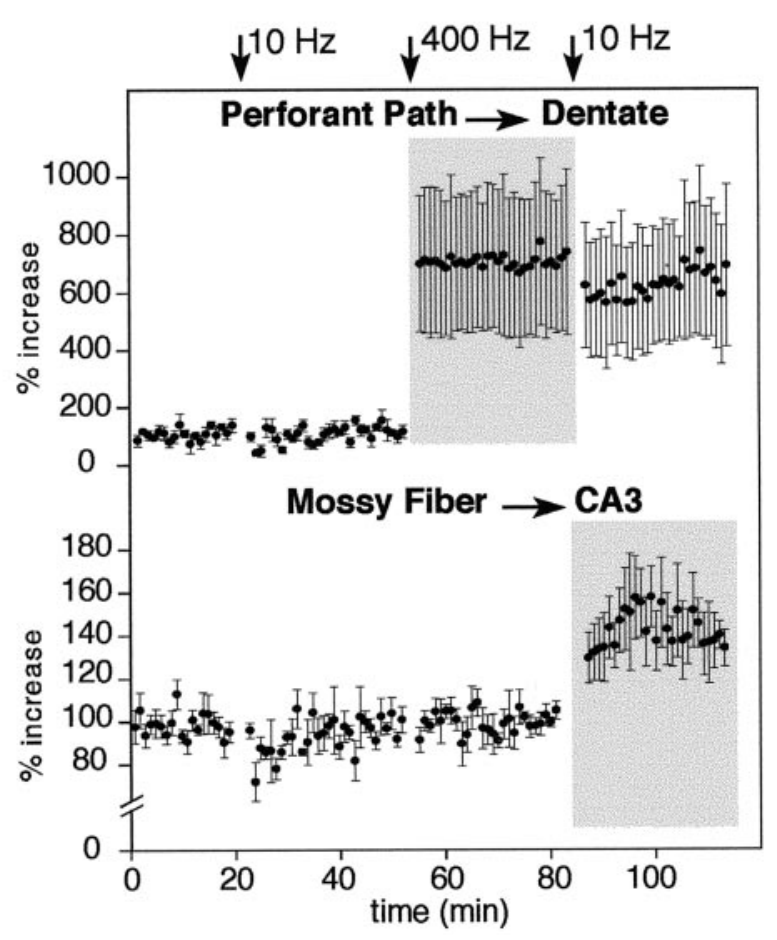

synaptically. Although sharing this common requirement, it has been demonstrated previously, and confirmed here in vivo, that the cellular/molecular mechanisms triggered when that critical level of excitatory input is reached are different for the two populations of synapses; perforant path LTP is NMDA receptor-dependent, whereas mossy fiber LTP is not (Harris and Cotman, 1986; Wigstrom et al., 1986). The cellular/molecular differences underlying the induction of LTP for these different subsets of synapses also may account for the differences in the optimal tetanization parameters necessary for inducing LTP. At lower frequencies of stimulation, LTP of perforant path input to the dentate was not induced because stimulation at $10-15 \mathrm{~Hz}$ does not result in sufficient depolarization to relieve the $\mathrm{Mg}^{2+}$ block of NMDA channels (Blanpied and Berger, 1992). When the frequency of entorhinal input 


\section{Perforant Path $\rightarrow$ Dentate}

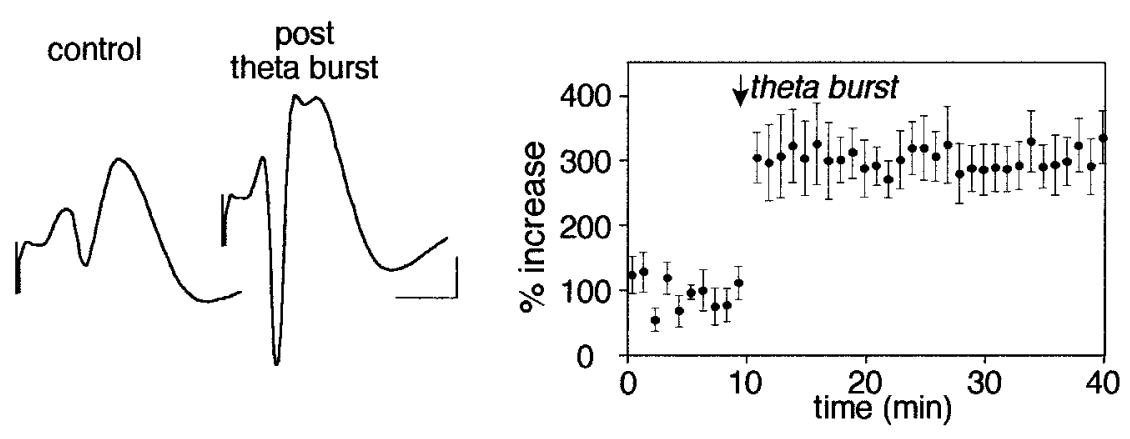

Figure 10. Multisynaptic induction of hippocampal LTP with theta-patterned stimulation. Schematic representation of the hypothesized pattern of input to granule cells of the dentate gyrus and CA3 pyramidal neurons using a stimulation pattern incorporating both high- and low-frequency impulses $(200 \mathrm{~Hz}$ bursts of 5 impulses at $10 \mathrm{~Hz} ; 50$ bursts). Data show the consequences of theta-like patterns of perforant path ( $p p)$ activation (theta burst $)$ on the induction of LTP $(n=5)$. Error bars indicate SEM. LTP is induced both monosynaptically and transsynaptically (i.e., multisynaptically) for perforant path input to the dentate gyrus (monosynaptic LTP; top) and for mossy fiber $(m f)$ input to CA3 (transsynaptic LTP; bottom). Waveforms are averages of all responses evoked in the last $5 \mathrm{~min}$ of a sample period. Calibration bars, 1 $\mathrm{mV}$ and $5 \mathrm{msec}$.

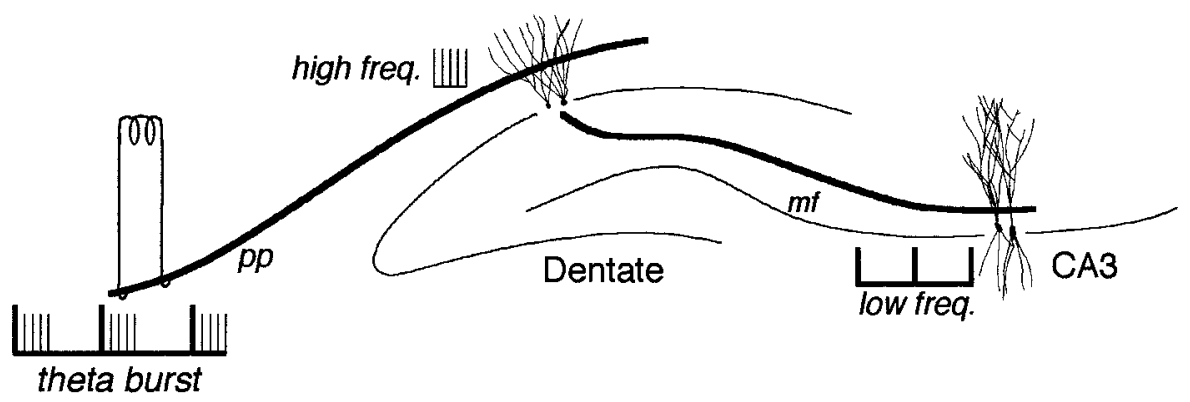

\section{Mossy Fiber $\rightarrow$ CA3}
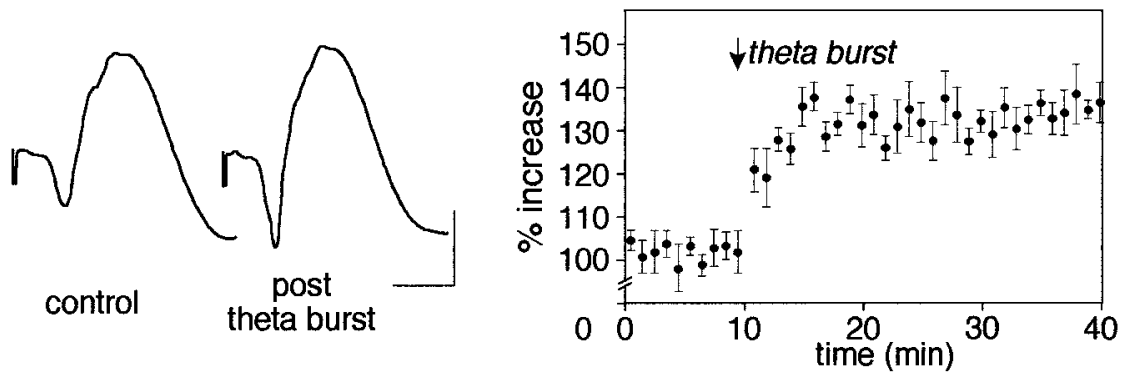

increases to $\geq 50-100 \mathrm{~Hz}$, temporal summation of perforant path input increases sufficiently for NMDA receptor activation and, thus, for the induction of LTP (Collingridge et al., 1988). At the level of mossy fiber input to CA3, frequencies of $\geq 50-100 \mathrm{~Hz}$ within the perforant path are not efficiently transmitted transsynaptically, and as a result, the induction of LTP is restricted to monosynaptically activated synapses. Although entorhinal activity in the range of $10-15 \mathrm{~Hz}$ does not lead to LTP of perforant path synapses, it does lead to frequency facilitation, i.e., a progressive increase in the number of active granule cells distributed over a wider spatial extent of the dentate gyrus. Because of the high degree of convergence of granule cell projections onto CA3 pyramidal cells, the increased number of active granule cells leads to greater levels of excitatory input sufficient to induce LTP of mossy fiber synapses within CA3. Theta burst stimulation incorporates input parameters optimal for potentiation of both perforant path and mossy fiber synapses, and as a result, LTP is induced monosynaptically and transsynaptically. Thus, potentiation of perforant path and mossy fiber synapses is achieved not only through two different mechanisms at the cellular/molecular level but also through two different mechanisms at the network level; the critical level of excitatory perforant path input to granule cells is reached as a consequence of temporal coincidence, whereas the critical level of mossy fiber excitation to CA 3 is reached as a consequence of spatial convergence.

More generally, the interaction between cellular/molecular constraints and network constraints illustrated by these results provides an empirical basis for the possibility that the spatial distribution of potentiated synapses within a neural network varies dynamically as a function of the temporal properties of afferent activity. The relevance of this finding to hippocampal function is based on the strong correspondence between the stimulation parameters used here and the temporal characteristics of action potential activity of hippocampal and entorhinal cortical neurons observed in the behaving animal (Ranck, 1973; Berger et al., 1983). Further elaboration of this basic principle may provide a basis for understanding several well documented properties of hippocampal neuronal population activity that evolve as a consequence of associative learning in the intact animal: the nonuniform spatial distribution of hippocampal neurons expressing learning-enhanced activity (i.e., "neural correlates") (O'Keefe, 1979; Berger et al., 1983; Eichenbaum et al., 1989), the dependence of a particular spatial distribution of neural correlates on task requirements and behavioral context (Christian and Deadwyler, 1986; Wiener et al., 1989), 

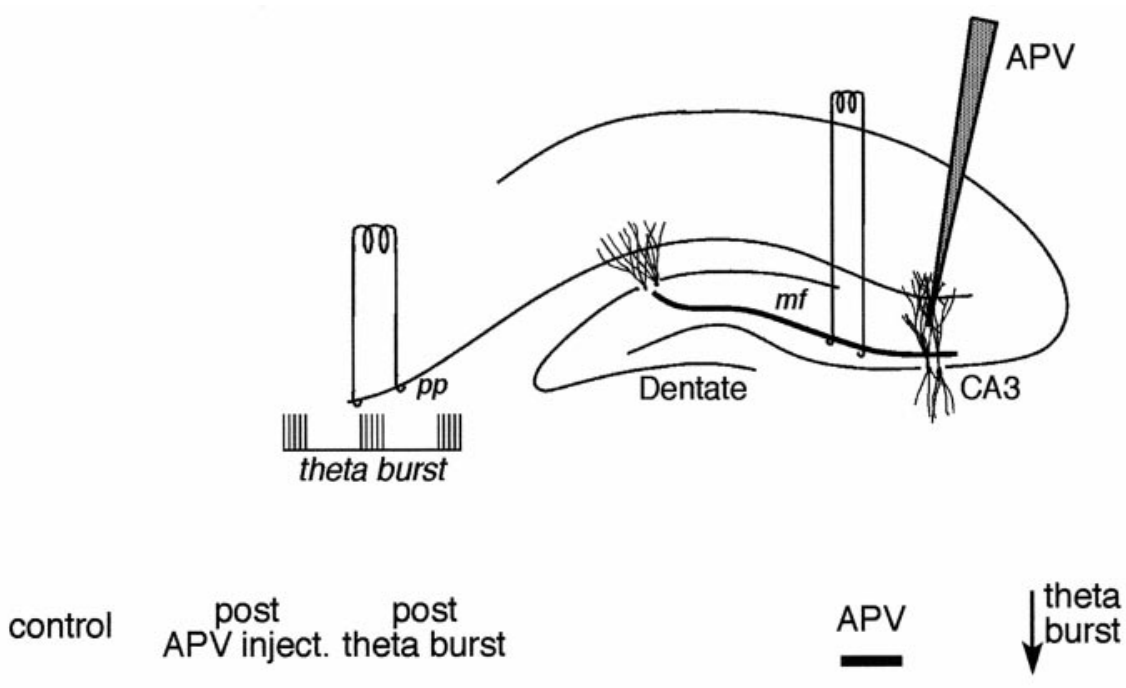

\section{Perforant Path $\rightarrow$ Dentate}

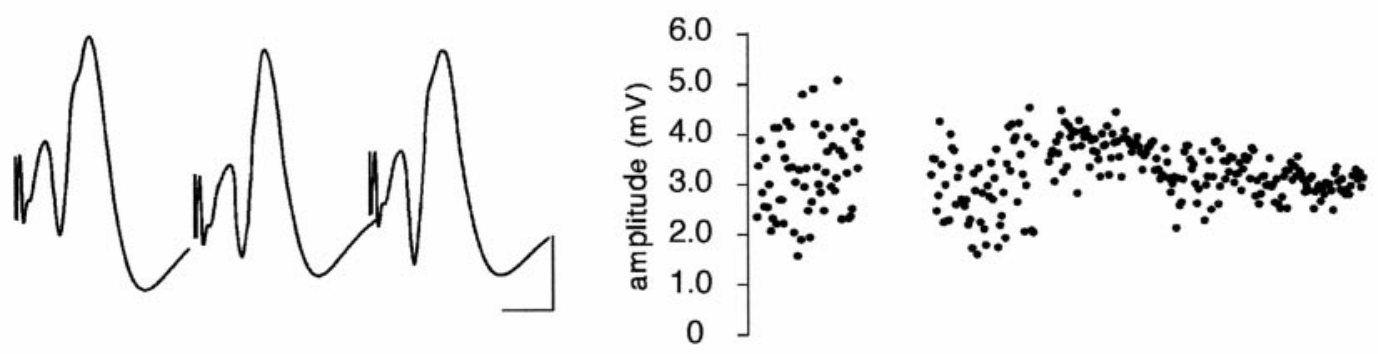

Perforant Path $\rightarrow$ CA3
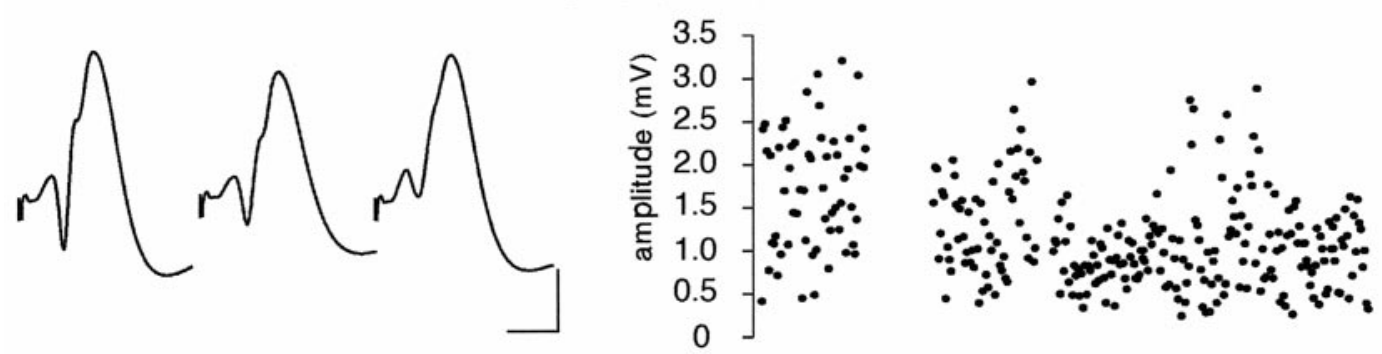

\section{Mossy Fiber $\rightarrow$ CA3}
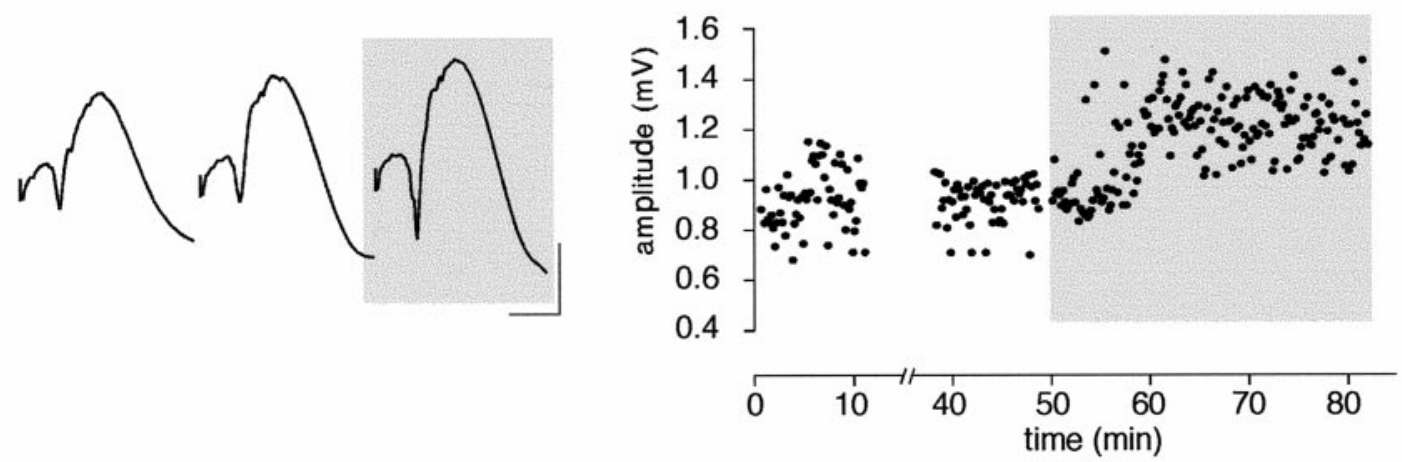

Figure 11. NMDA-independent induction of transsynaptic LTP. Pressure ejection of the NMDA receptor antagonist D-APV (100 $\mu \mathrm{M}$; $\sim 70 \mathrm{nl} / \mathrm{min}$ for 15-30 min) into the apical dendrites of the CA3 and the dentate gyrus before theta burst stimulation blocked the induction of perforant path ( $p p$ ) LTP (for both monosynaptic input to CA3 and the dentate) but not transsynaptic mossy fiber $(\mathrm{mf}) \mathrm{LTP}$ (waveforms are averages of responses collected during last $5 \mathrm{~min}$ of a given sample period). Calibration bars, $1 \mathrm{mV}$ and $5 \mathrm{msec}$. 
and the functional importance of the characteristic theta rhythmicity of hippocampal neural activity (Berry and Thompson, 1978; Otto et al., 1991).

\section{REFERENCES}

Alonso A, Garcia-Austt E (1987) Neuronal sources of theta rhythm in the entorhinal cortex of the rat. II. Phase relations between unit discharges and theta field potentials. Exp Brain Res 67:502-509.

Amaral DG, Witter MP (1989) The three-dimensional organization of the hippocampal formation: a review of anatomical data. Neuroscience 31:571-591.

Amaral DG, Ishizuka N, Claiborne B (1990) Neurons, numbers and the hippocampal network. In: Understanding the brain through the hippocampus: the hippocampal region as a model for studying structures and function (Storm-Mathisen J, Zimmer J, Ottersen OP, eds), pp 1-11. Amsterdam: Elsevier.

Andersen P, Bliss TVP, Skrede KK (1971) Unit analysis of hippocampal population spikes. Exp Brain Res 13:208-221.

Andersen P, Sundberg SH, Sveen O (1977) Specific long-lasting potentiation of synaptic transmission in hippocampal slices. Nature 266:736-737.

Bekkers JM, Stevens CF (1990) Presynaptic mechanism for long-term potentiation in the hippocampus. Nature 346:724-729.

Berger TW (1984) Long-term potentiation of hippocampal synaptic transmission affects rate of behavioral learning. Science 627-630.

Berger TW, Sclabassi RJ (1988) Long-term potentiation and its relation to hippocampal pyramidal cell activity and behavioral learning during classical conditioning. In: Long-term potentiation: from biophysics to behavior (Landfield PW, Deadwyler SA, eds), pp 467-497. New York: Liss.

Berger TW, Yeckel MF (1991) Long-term potentiation of entorhinal afferents to the hippocampus: enhanced propagation of activity through the trisynaptic pathway. In: Long-term potentiation: a debate of current issues (Baudry M, Davis JL, eds), pp 327-356. Cambridge, MA: MIT.

Berger TW, Rinaldi P, Weisz DJ, Thompson RF (1983) Single unit analysis of different hippocampal cell types during classical conditioning of the rabbit nictitating membrane response. J Neurophysiol 50:1197-1221.

Berger TW, Yeckel MF, Thiels E (1997) Network determinants of hippocampal synaptic plasticity. In: Long-term potentiation, Vol 3 (Baudry M, Davis JL, eds), pp 233-267. Cambridge, MA: MIT.

Berry SD, Thompson RF (1978) Prediction of learning rate from the hippocampal electroencephalogram. Science 200:1298-1300.

Blanpied TA, Berger TW (1992) Characterization in vivo of the NMDA receptor-mediated component of dentate granule cell population synaptic responses to perforant path input. Hippocampus 2:373-388.

Bliss TVP, Collingridge GL (1993) A synaptic model of memory-longterm potentiation in the hippocampus. Nature 361:31-39.

Christian EP, Deadwyler SA (1986) Behavioral functions and hippocampal cell types: evidence for two nonoverlapping populations in the rat. J Neurophysiol 55:331-348.

Claiborne BJ, Amaral DG, Cowan WM (1986) A light and electron microscope analysis of the mossy fibers of the rat dentate gyrus. J Comp Neurol 246:435-458.

Claiborne BJ, Xiang Z, Brown TH (1993) Hippocampal circuitry complicates analysis of long-term potentiation in mossy fiber synapses. Hippocampus 3:115-122.

Collingridge GL, Herron CE, Lester RAJ (1988) Frequency-dependent $N$-methyl-D-aspartate receptor-mediated transmission in rat hippocampus. J Physiol (Lond) 399:301-312.

Davies SN, Lester RA, Reymann KG, Collingridge GL (1989) Temporally distinct pre- and post-synaptic mechanisms maintain long-term potentiation. Nature 338:500-503.

Derrick BE, Martinez JL (1994) Frequency-dependent associative longterm potentiation at the hippocampal mossy fiber-CA3 synapse. Proc Natl Acad Sci USA 91:10290-10294.

Eichenbaum H, Wiener SI, Shapiro ML, Cohen NJ (1989) The organization of spatial coding in the hippocampus: a study of neural ensemble activity. J Neurosci 9:2764-2775.

Foster TC, McNaughton BL (1991) Long-term potentiation of CA1 synaptic transmission is due to increased quantal size, not quantal content. Hippocampus 1:79-91.

Freeman JA, Nicholson C (1975) Experimental optimization of current source-density technique for anuran cerebellum. J Neurophysiol 38:369-382.

Gaarskjaer FB (1978) Organization of the mossy fiber system of the rat studied in extended hippocampi. I. Terminal area related to number of granule and pyramidal cells. J Comp Neurol 178:49-72.
Harris EW, Cotman CW (1986) Long-term potentiation of guinea pig mossy fiber responses is not blocked by $N$-methyl-D-aspartate antagonists. Neurosci Lett 70:132-137.

Ishizuka N, Weber J, Amaral DG (1990) Organization of intrahippocampal projections originating from $\mathrm{CA} 3$ pyramidal cells in the rat. J Comp Neurol 295:580-623.

Kelso SR, Ganong AH, Brown TH (1986) Hebbian synapses in the hippocampus. Proc Natl Acad Sci USA 83:5326-5330.

Landfield PW, Deadwyler SA, eds (1988) Long-term potentiation: from biophysics to behavior. New York: Liss.

Langdon RB, Johnson JW, Barrionuevo G (1993) Asynchrony of mossy fibre inputs and excitatory postsynaptic currents in rat hippocampus. J Physiol (Lond) 472:157-176.

Larson J, Lynch G (1986) Induction of synaptic potentiation in hippocampus by patterned stimulation involves two events. Science 232:985-988.

Lorente de Nó R (1933) Studies on the structure of cerebral cortex. II. Continuation of the study of the ammonic system. J Psychol Neurol 45:381-438

Malenka RC, Kauer JA, Zucker RS, Nicoll RA (1988) Postsynaptic calcium is sufficient for potentiation of hippocampal synaptic transmission. Science 242:81-84.

McNaughton BL, Douglas RM, Goddard GV (1978) Synaptic enhancement in fascia dentata: cooperativity among coactive afferents. Brain Res 157:277-293.

Morris RGM (1989) Synaptic plasticity and learning: selective impairment of learning in rats and blockade of long-term potentiation in vivo by the $N$-methyl-D-aspartate receptor antagonist AP5. J Neurosci 9:3040-3057.

Munoz MD, Nunez A, Garcia-Austt E (1991) Frequency potentiation in granule cells in vivo at theta frequency perforant path stimulation. Exp Neurol 113:74-78.

O'Keefe J (1979) A review of the hippocampal place cells. Prog Neurobiol 13:419-439.

Otto T, Eichenbaum H, Weiner SI, Wible CG (1991) Learning-related patterns of CA1 spike trains parallel stimulation parameters optimal for inducing hippocampal long-term potentiation. Hippocampus 1:181-192.

Ranck Jr JB (1973) Studies on single neurons in dorsal hippocampal formation and septum in unrestrained rats. Part I. Behavioral correlates and firing repertoires. Exp Neurol 41:461-531.

Rose GM, Dunwiddie TV (1986) Induction of hippocampal long-term potentiation using physiologically patterned stimulation. Neurosci Lett 69:244-248.

Steward O, Scoville SA (1976) Cells of origin of entorhinal cortical afferents to the hippocampus and fascia dentate of the rat. J Comp Neurol 169:347-370.

Swanson LW, Wyss JM, Cowan WM (1978) An autoradiographic study of the organization of intrahippocampal association pathways in the rat. J Comp Neurol 181:681-716.

Tamamaki N, Nojyo Y (1993) Projection of the entorhinal layer II neurons in the rat as revealed by intracellular pressure-injection of neurobiotin. Hippocampus 3:471-480.

Wiener SI, Paul CA, Eichenbaum H (1989) Spatial and behavioral correlates of hippocampal neuronal activity. J Neurosci 9:2737-2763.

Wigstrom H, Gustafsson B (1983) Facilitated induction of hippocampal long-lasting potentiation during blockade of inhibition. Nature 301:603-604.

Wigstrom H, Gustafsson B, Huang YY (1986) Mode of action of excitatory amino acid receptor antagonists on hippocampal long-lasting potentiation. Neuroscience 17:1105-1115.

Williams SH, Johnston D (1991) Kinetic properties of two anatomically distinct excitatory synapses in hippocampal CA3 pyramidal neurons. J Neurophysiol 66:1010-1020.

Witter MP (1993) Organization of the entorhinal hippocampal system a review of current anatomical data. Hippocampus 3:33-44.

Yeckel MF, Berger TW (1990) Feedforward excitation of the hippocampus by afferents from the entorhinal cortex: redefinition of the role of the trisynaptic pathway. Proc Natl Acad Sci USA 87:5832-5836.

Yeckel MF, Berger TW (1995a) Characterization of mossy fiber-evoked responses in the CA3 subfield, in vivo. Soc Neurosci Abstr 21:1437.

Yeckel MF, Berger TW (1995b) Monosynaptic excitation of hippocampal CA1 pyramidal cells by afferents from the entorhinal cortex. Hippocampus 5:108-114.

Zalutsky RA, Nicoll RA (1990) Comparison of two forms of long-term potentiation in single hippocampal neurons. Science 248:1619-1624. 